\title{
مسارات الاعتراف وسؤال الغيرية عند بول ريكور
}

\section{Paths to Recognition and the Question of Relationship with the other by Paul Ricoeur}

$$
\begin{aligned}
& \text { ملخص: تشتمل هذه الدراسة على ثلاثة أقسام؛ خصصنا الأول منها للنظر في الدلالات }
\end{aligned}
$$

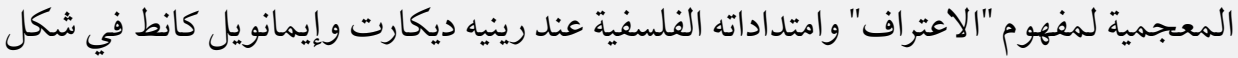

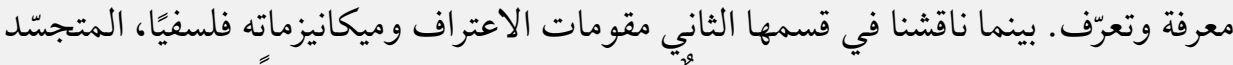

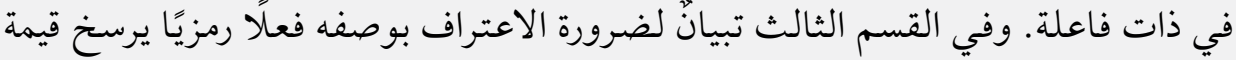

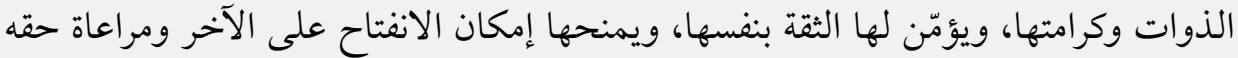

$$
\begin{aligned}
& \text { في ممارسة هويته، وفت مبدأ أسبقية الاختلاف على الثقلى التشابه والتماثل. }
\end{aligned}
$$

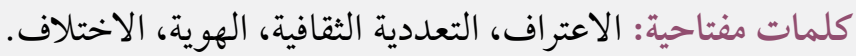

Abstract: Our article came divided into three instants. We have devoted its principle to considering the lexical connotations of the concept of recognition and its philosophical extensions as it occurred in both Descartes' and Kant's approaches in the form of "knowledge and knowing". In the second instant, we discussed the elements of the philosophical recognition that is embodied in a human self capable of remembering the promise and the gift. The process culminated in a third instant in which the need for recognition as a symbolic act that entrenches the value and dignity of the self, secures confidence in itself, enables it to be open on the other while taking into account his right to exercise his identity under the principle of the priority of difference over similarity and equivalence.

Keywords: Recognition, Multiculturalism, Identity, Difference.

$$
\text { * باحث في الفلسفة الإسلامية والحديثة. حاصل على إجازة في الفلسفة من كلية الآداب والعلوم الإنسانية بمراكش (المغرب). }
$$
A researcher in Islamic and modern philosophy. He holds a Bachelor's degree in philosophy from the Faculty of Arts and Humanities in Marrakech (Morocco). 
يسعى الفيلسوف بول ريكور Paul Ricœur (1913-2005) من وراء مساءلة مفهوم الاعتراف

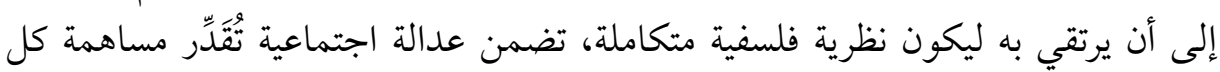

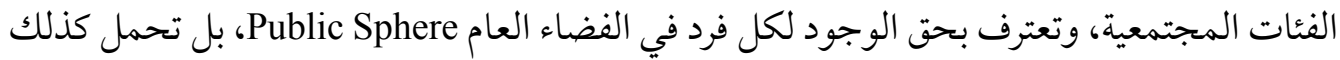

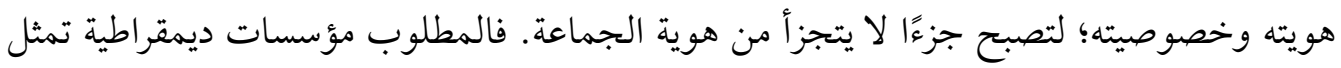

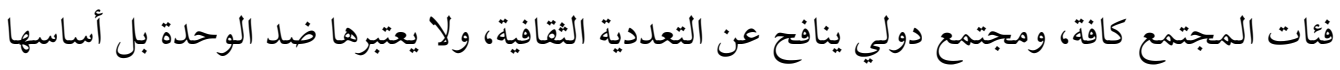

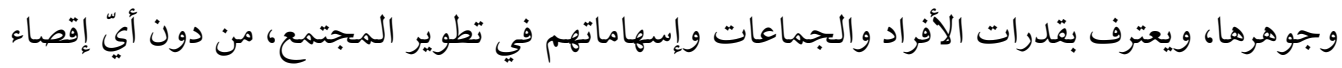

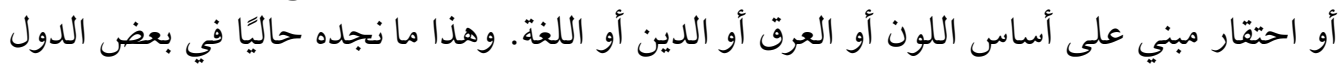

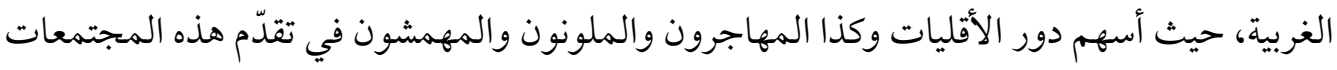
المستَقِبلة؛ ما يجعل من القمين الانفتاح على هذا الاعتراف، ومحاولة اكتناه مناحيه الفلسفية واللغوية. سنتاول ماهية الاعتراف من الناحية المعجمية اللغوية، وكيفية تأسيس فلسفته من منطلق

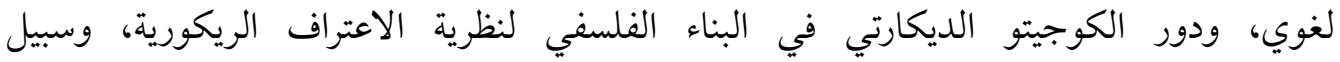

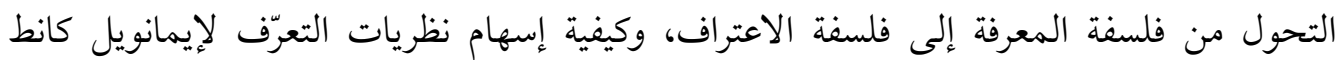
لمent Immanuel Kant لفريدريش هيغل Friedrich Hegel (1770-1831) في هذا التحول، فضلاً عن نتائج هذا التحول نفسه.

\section{أولاً: البناء الإشكالي لمفهومر الاعتراف:

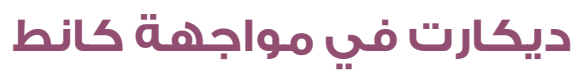
اختار بول ريكور البحث القاموسي مدخلاً لَسَوْق مجموع إشكالات الاعتراف بداية من القرن التاسع عشر الميلادي، فاعتمد قاموس اللغة الفرنسية Dictionnaire de la langue française (1863) لإيميل

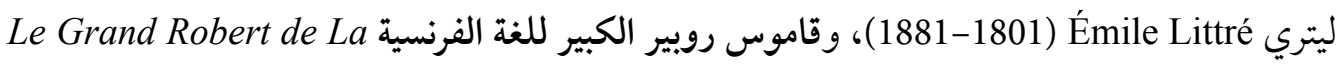
الفظة Langue Française

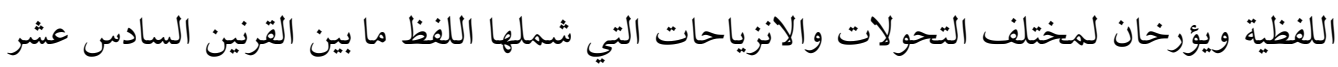

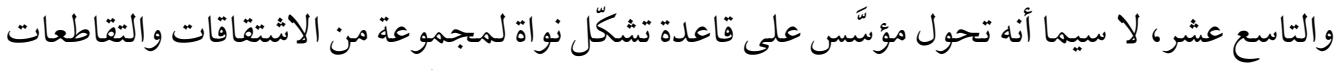

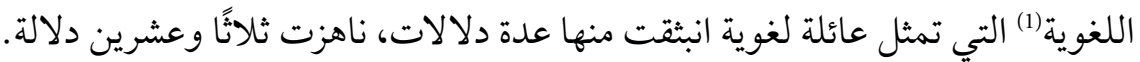

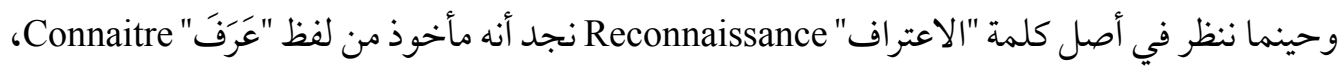

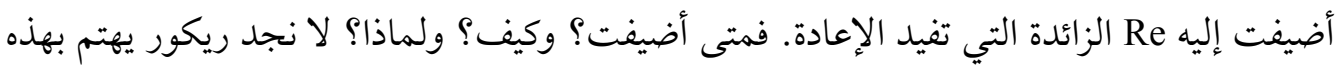

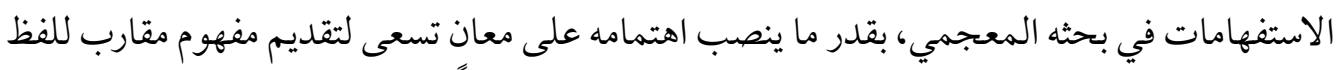

(1) Paul Ricœur, Parcours de la reconnaissance (Paris: Gallimard, 2004), p. 17.

رجعنا كذلك إلى الترجمة العربية، ينظر: بول ريكور، سيرة الاعتراف، ترجمة فتحي إنتزو، مراجعة محمد محجوب (تونس: المركز

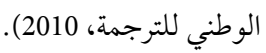


"Connaitre

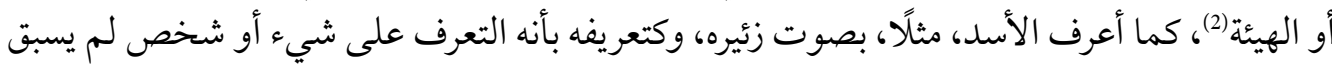

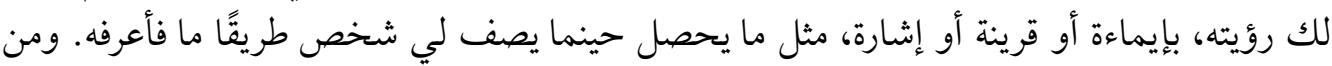

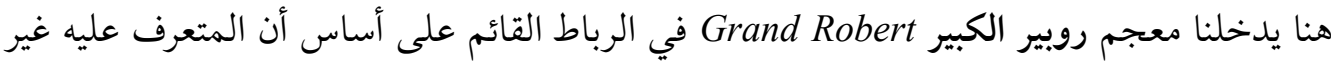
بِيِّن بنفسه، يحتاج إلى مزيد من الكشف والإيضاح. فهل يحتاج موضوع المعرفة إلى سند خارجي؟

\section{1. ديكارت: تمييز الصادق مـن الكاذب}

استثمر بول ريكور بحث رينيه ديكارت René Descartes (1596-1650)، لفعل الاعتراف من منطوق

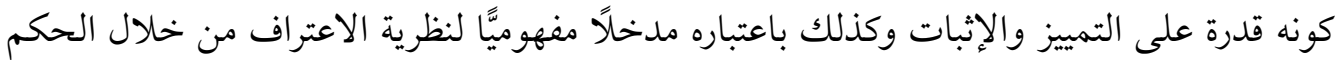

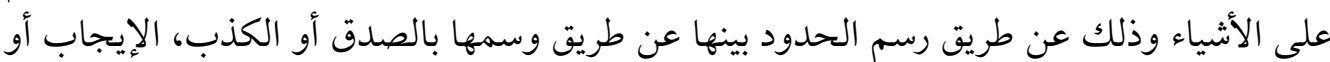

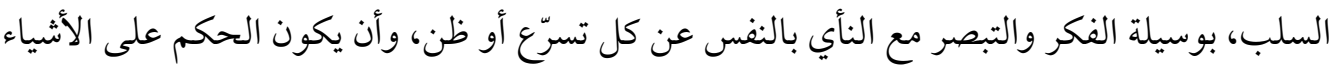

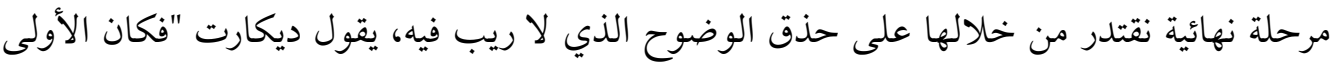

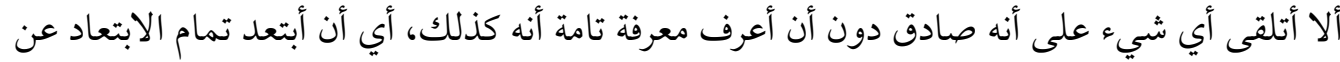

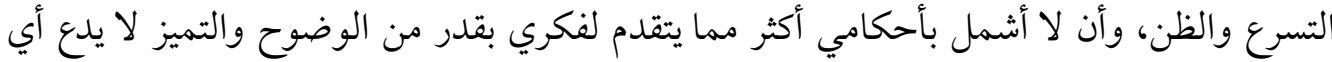

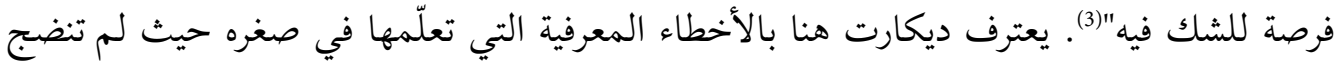

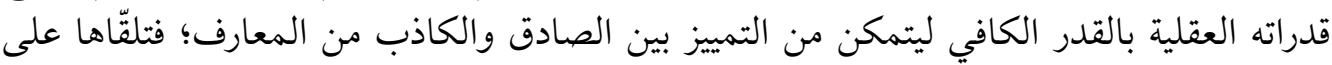

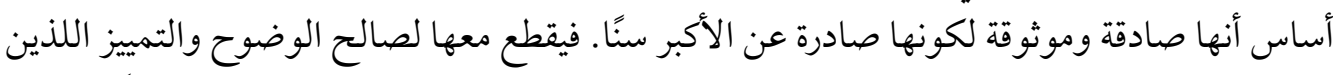

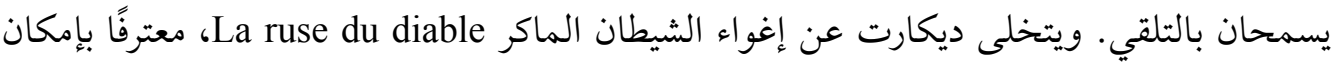

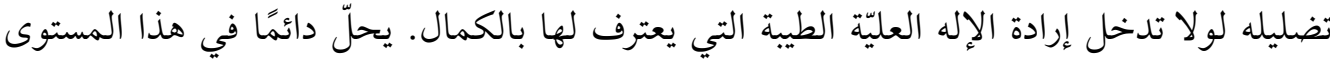

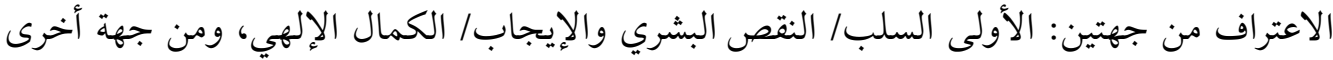

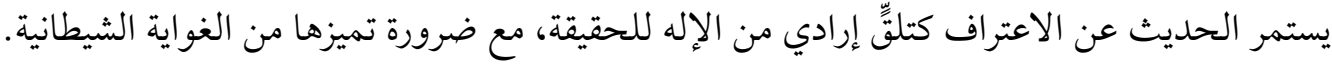

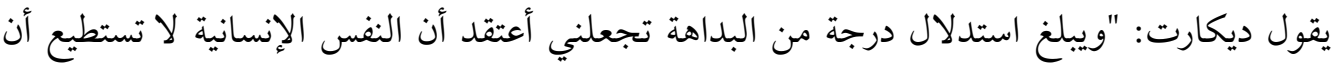

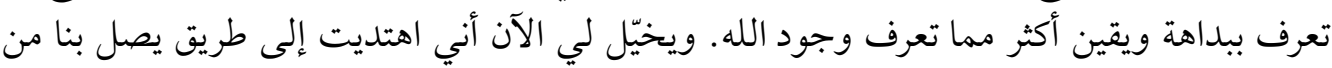

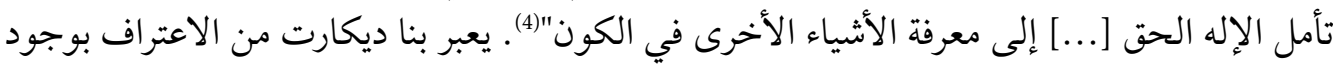
بداهة ويقين إلى الإقرار والحكم بوجود نقص في الأشياء. يصرح ديكارت: "ثم إني أعرف بخدي فئرتي

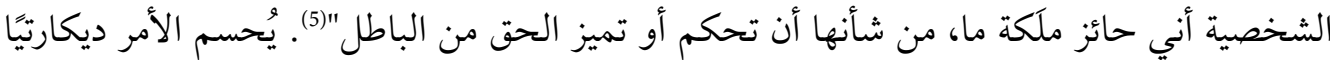

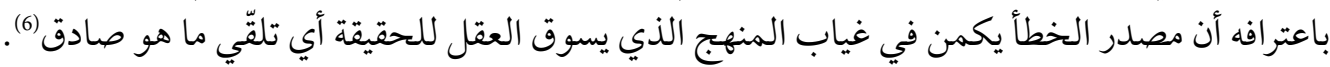

(2) Ricœur, p. 21.

(3) رينيه ديكارت، حديث الطريقة، ترجمة وشرح وتعليق عمر الشارني (بيروت: المنظمة العربية للترجمة، 2008)، ص 94-96،

(4) رينيه ديكارت، التأملات في الفلسفة الأولى، ترجمة وتقديم وتعليق عثمان أمين، سلسلة ميراث الترجمة 1297، ط 2 (القاهرة:

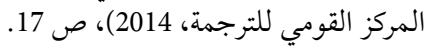
المرجع نفسه، ص صكترجه 179.

(6) Ricœur, p. 65. 


\section{2. كانط: الربط تحت ثرط الزمان}

يستعمل كانط الاعتراف بصيغة التعريف الذي لا يكون القصد منه الفصل والتمييز بين ماهية الأنا والغير كما حصل عند ديكارت، بقدر ما يعني الربط Relier. فمن خلال الربط بين العبن العقل والحس تصدي تصدر

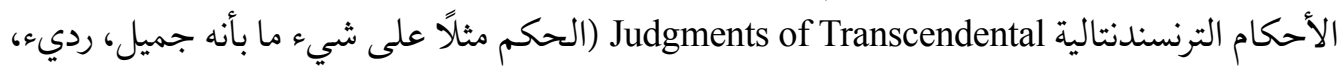

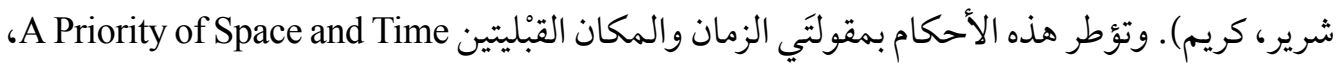

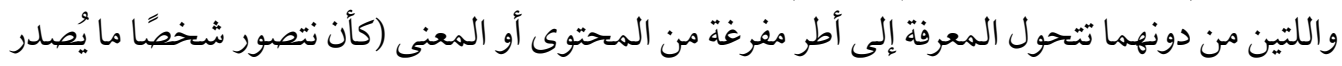

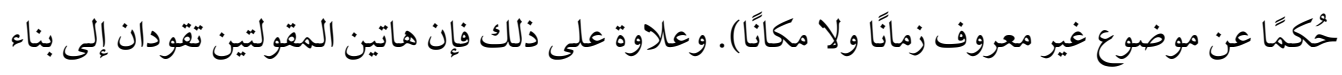

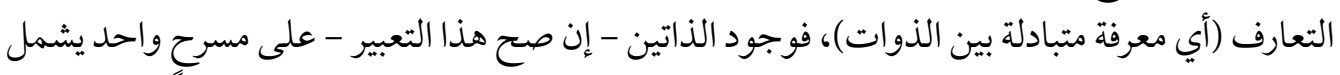

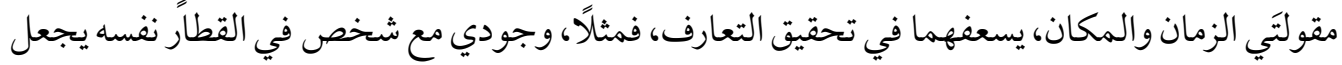

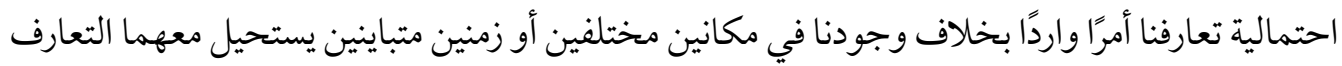

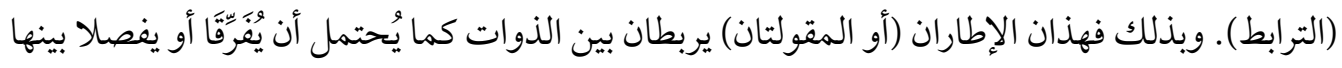

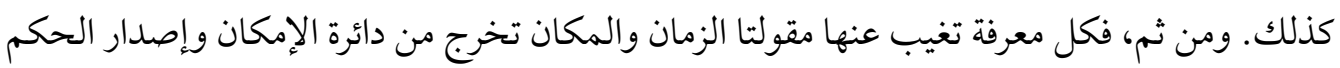

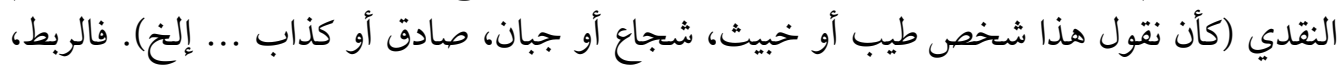

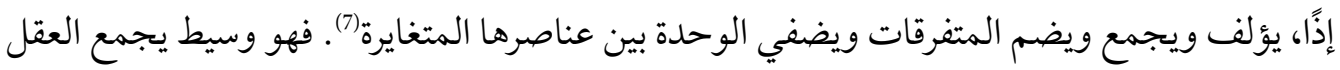

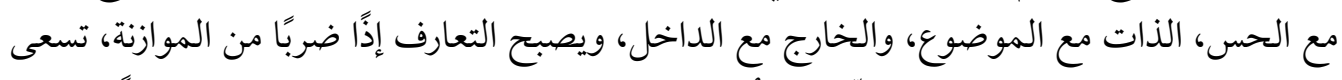

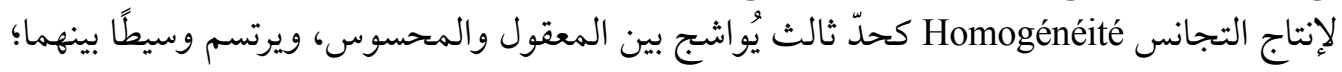
إذ إن دورها جذب الطرفين لإعادة بناء العالم الخارجي وتجديد مواضيعه التي تحصل داخل مكان وزمان

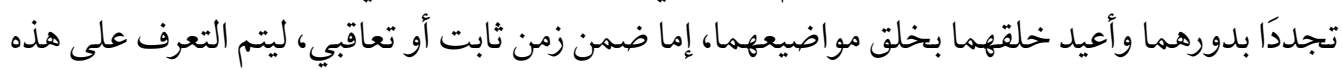

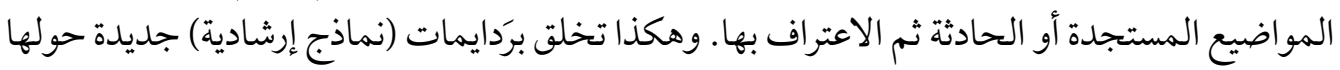
ما تفتأ تتطور ثم تنتهي مدة صلاحيتها وتُنشِئ مواضيع جديدة في أعقابها، وهكذا دواليك. لا يثق كانط باحتمال المعارفة بالقطيعة المطلقة بين وجهة النظر العقلانية والتجريبية، بل يجمعهما ويوحّد

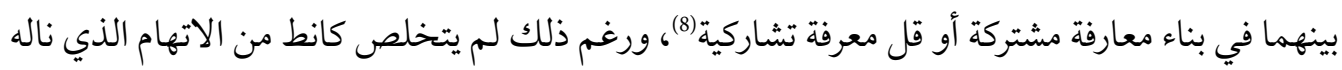

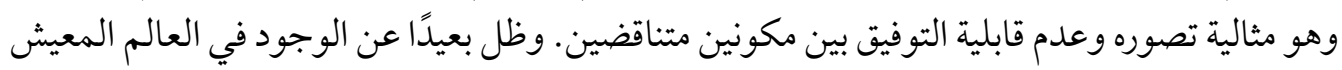
Lifeworld

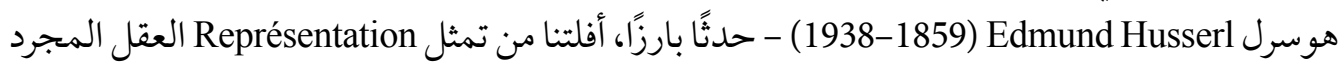

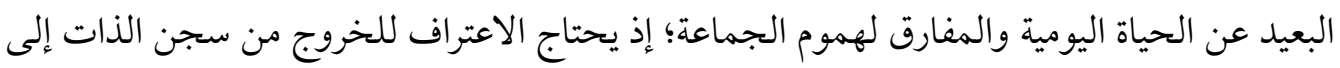

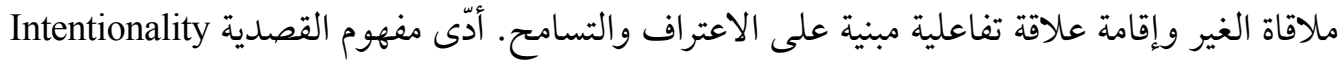

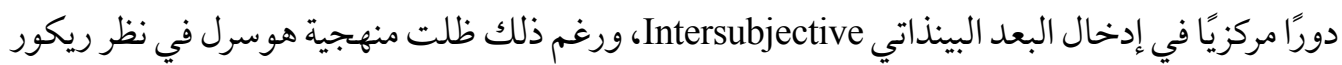
تعاني أحادية البعد وتقترب من معرفة الذات شرطًا أوليًا لبروز الاعتراف (9).

(7) Ibid., p. 79.

(8) Ibid., p. 93.

(9) Ibid. 
كابَد الموقف الديكارتي والكانطي التمركز حول الـ"أنا أفكر" أو حول موضوع المعرفة الترنسندنتالي Transcendental Knowledge والإهانة في بناء فلسفة الاعتراف The Philosophy of Recognition؛ إذ لتلك الأفعال (الاحتقار وغيره) أثثر في دفع الذوات للتمسك بهوياتها. فلولا هذه الأنواع من الاحتقار والتنكر التي لحقت الأقليات

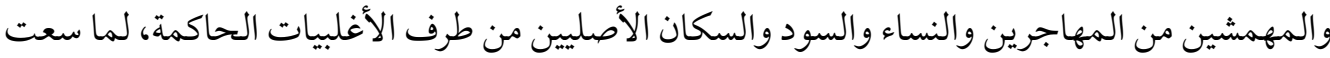
إلى إبراز ذاتها والدفاع عن هويتها مع محاولة نزع الاعتراف بكامل حقوقها المشروعة.

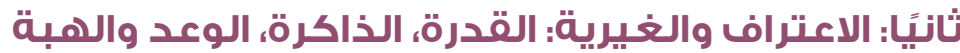

انطلاقًا من فلاسفة الريبة من أمثال كارل ماركس Karl Marx (1818-1883)، وفريدريك نيتشه Friedrich Nietzsche، وسيغموند فرويد Sigmund Freud (1856-1939)، يشكك ريكور في قدرات الكوجيتو الديكارتي، لا للتخلص منه، بل لتصحيحه وتقويمه، وتمكينه من استيعاب الجروح التي

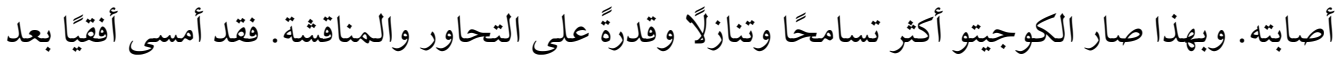

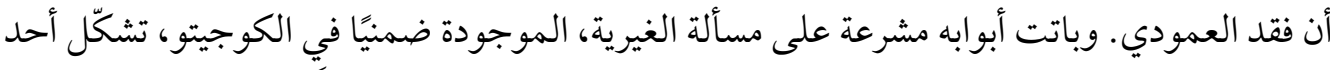

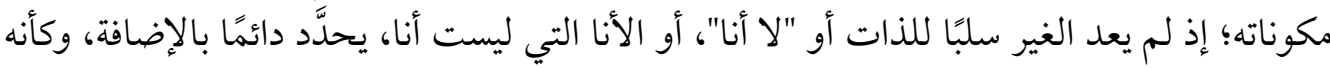

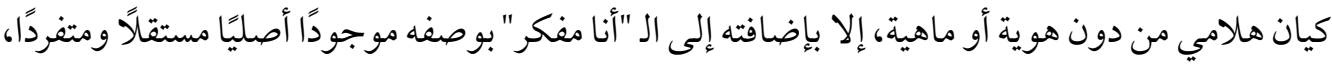

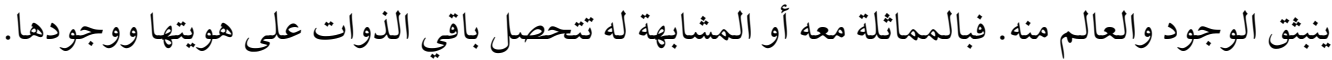

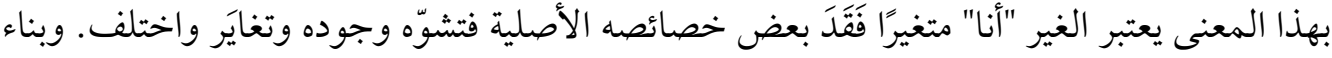

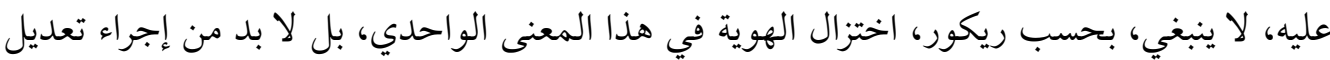

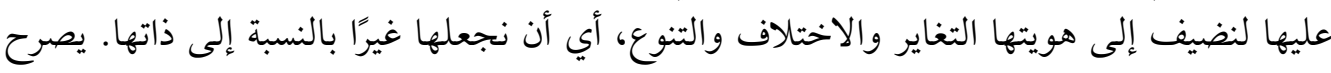

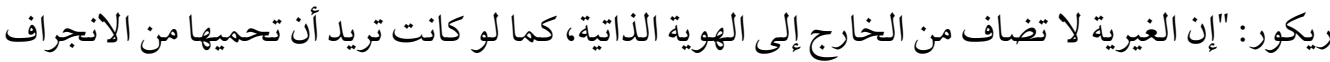
الأنوي Solipsiste ولكنها تنتمي إلى فحوى الهوية الذاتية وإلى تكوينها الأنطلوجي" (10.). فالهوية/ الأنا

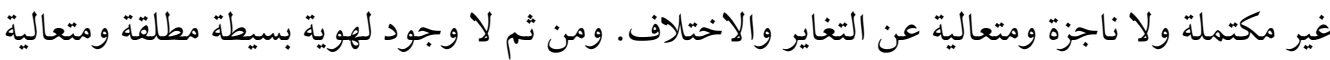

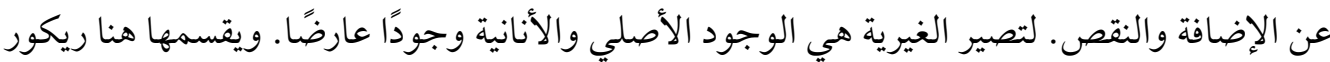

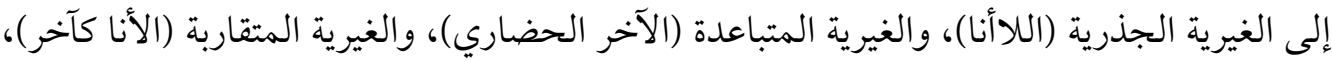

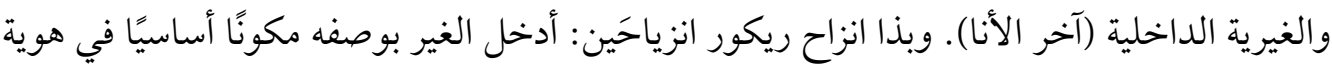

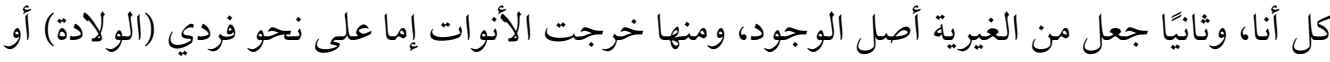

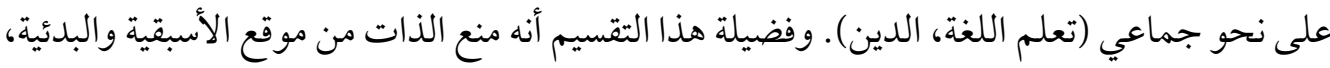
والذي يمنحها التأسيس لكل أنواع العلاقات في الكون.

هكذا، أعاد ريكور موقعة الغيرية بين الذات المتعجرفة كما الحال في فلسفات الكوجيتو الديكارتية،

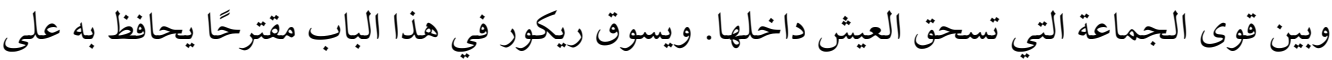

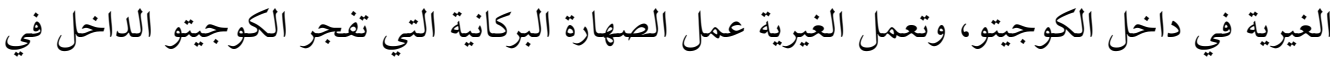




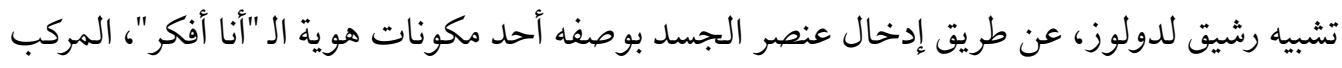

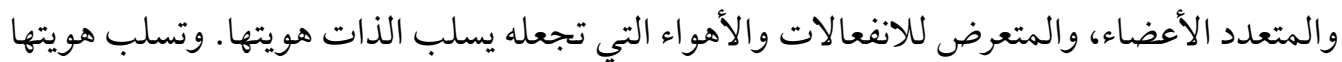

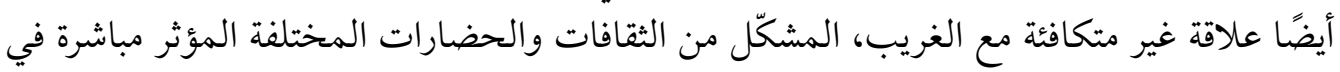

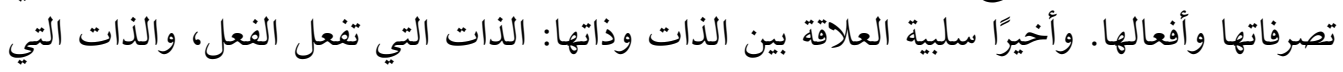

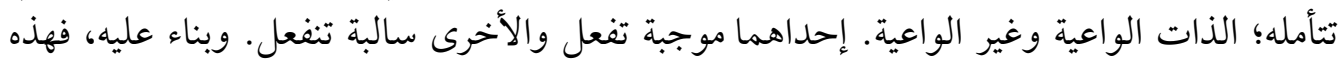

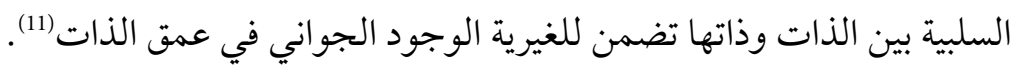

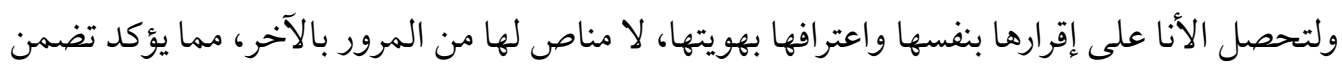

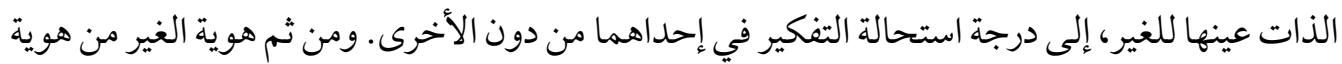

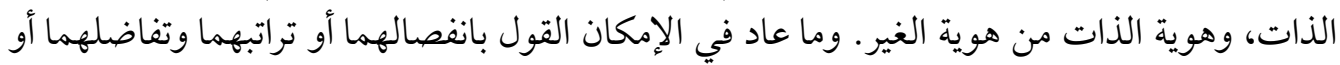

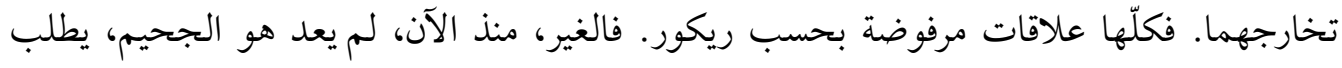

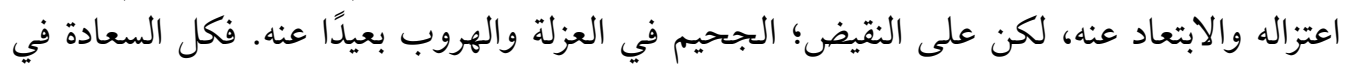

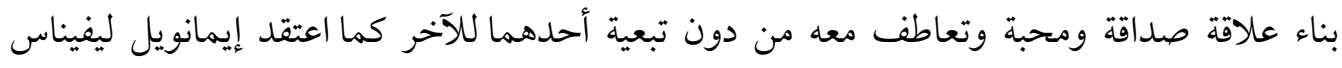
Emmanuel Levinas

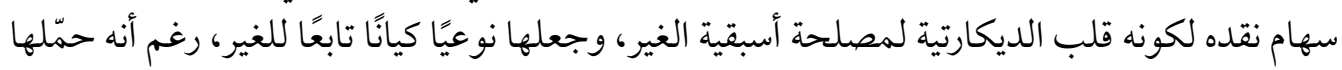

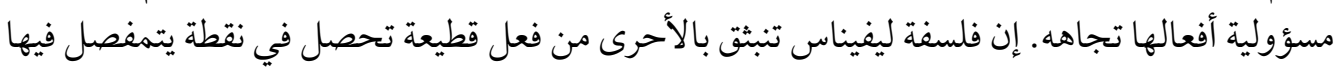

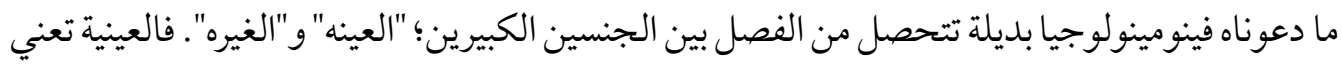

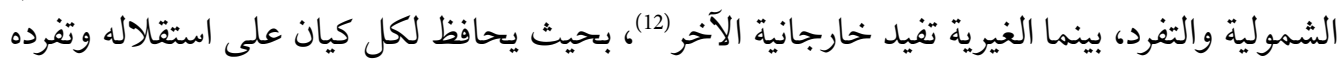

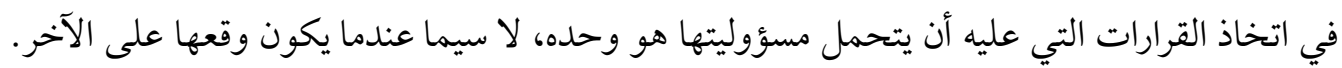

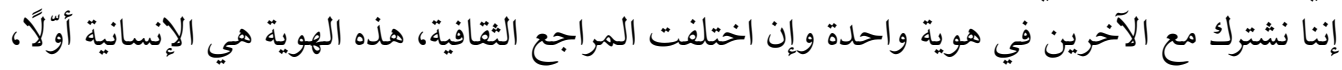

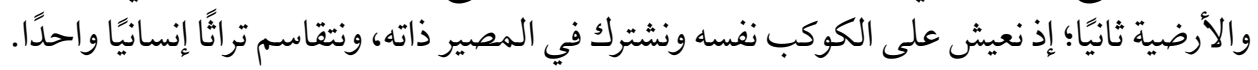

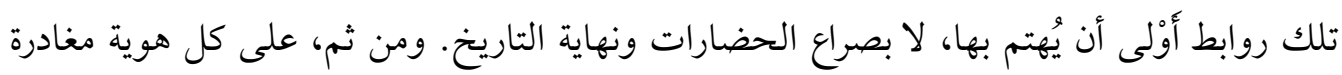

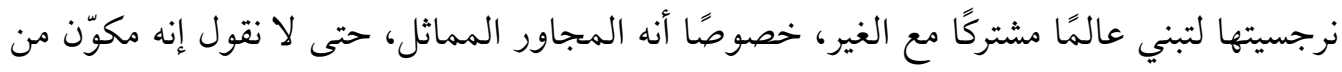

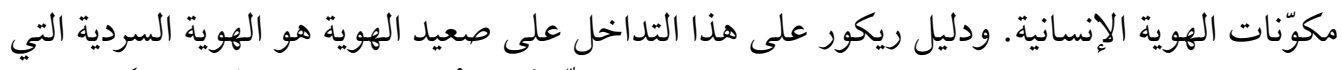

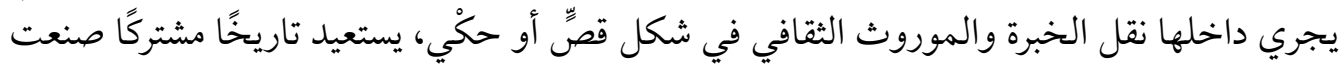

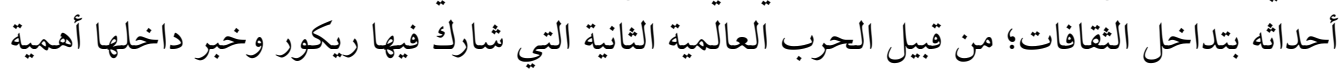

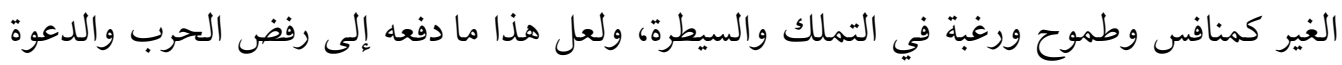

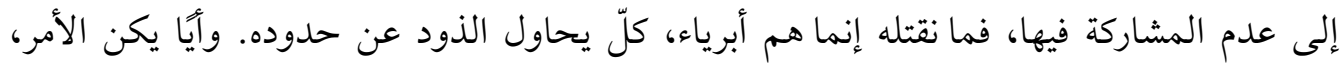

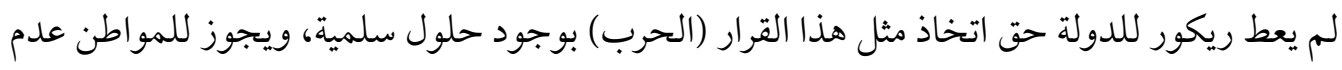

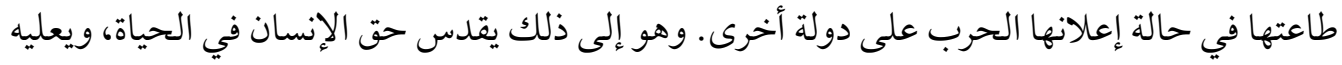

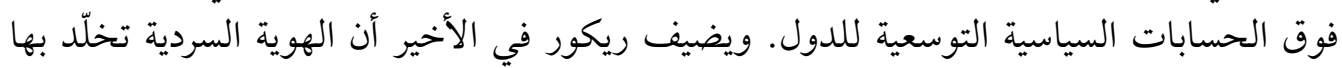




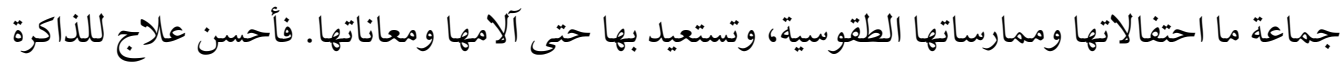

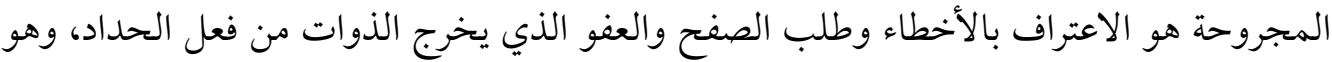

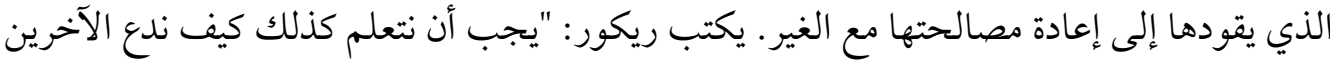

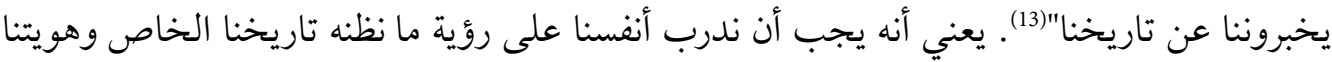

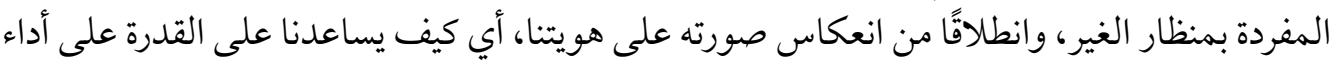

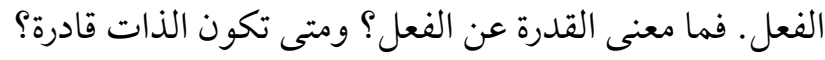

\section{1. فينومينولوجيا الإنسان القادر}

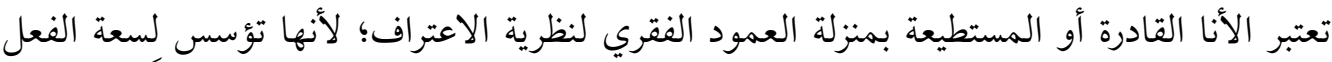

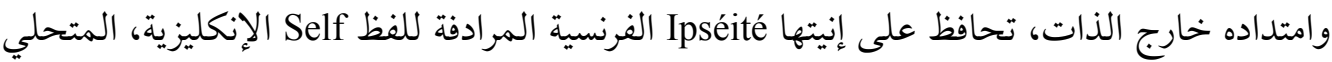

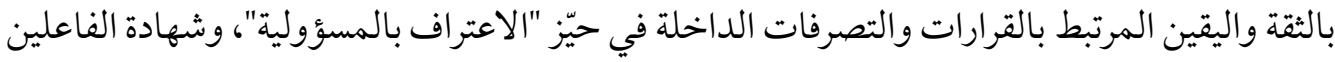

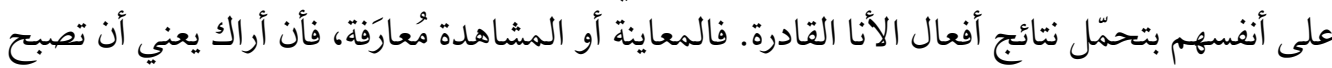

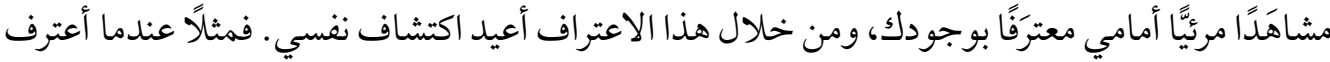

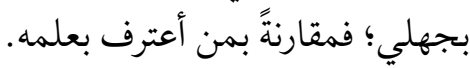

يعرج ريكور في هذا السياق على فلسفة اللغة قصد استطلاع معاني الفعل وقد تحوّل إلى محكي إلى إلى إنساء

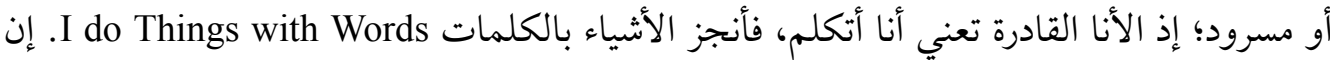

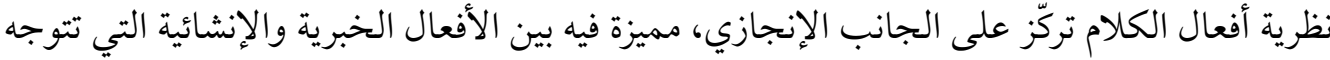

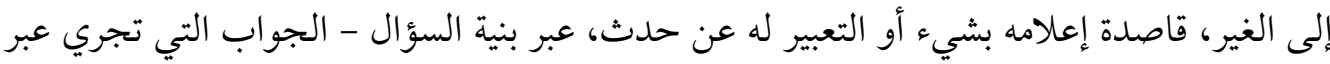

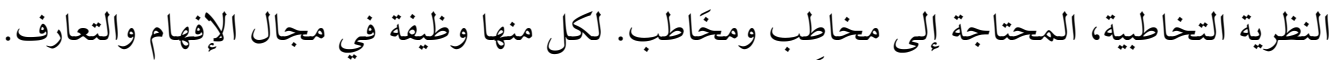

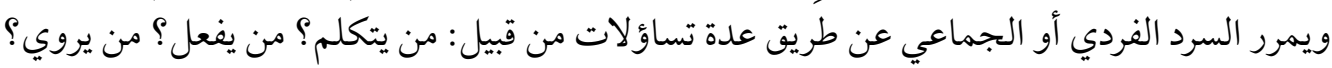

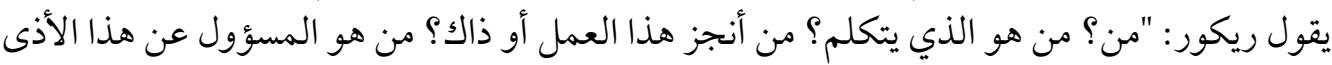

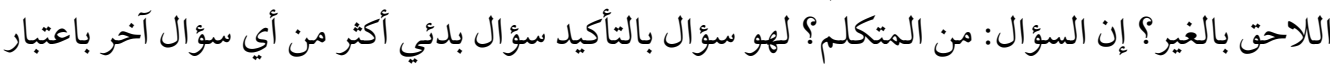
أن باقي الأسئلة الأخرى تقتضي استعمال (الكلام)"(14).

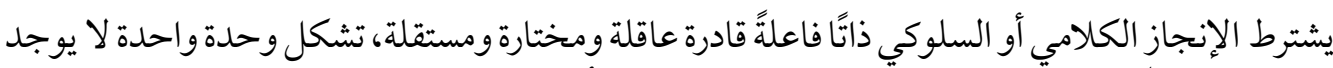

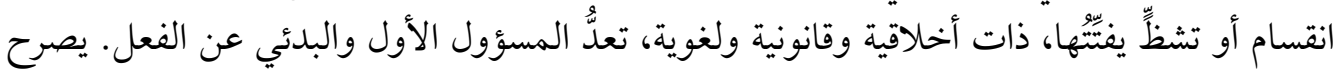

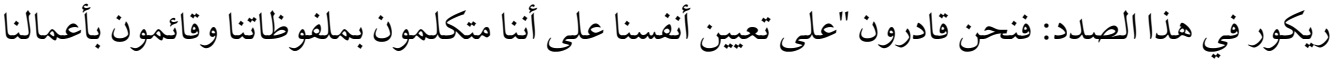

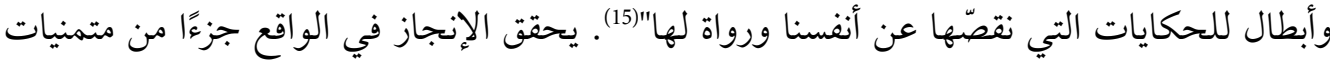

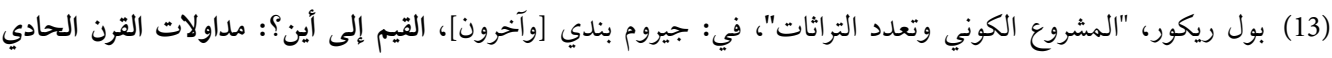

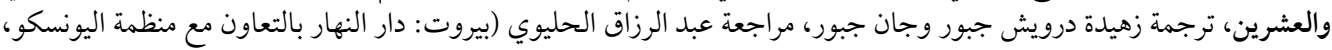
(2004)، ص 85 (14) بول ريكور، العادل، ترجمة محمد البحري [وآخرون] (قرطاج: المجمع التونسي للعلوم والآداب والفنون بيت الحكمة، 
الذات وآمالها وطموحاتها. وقد لا يتناسب المتحقِّق على أرض الواقع مع المتمنيات، فينجز شيئًا آخر.

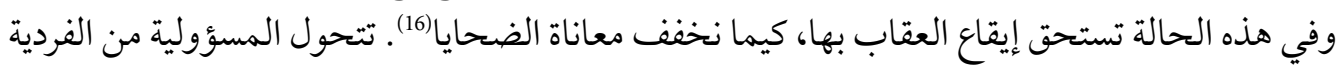

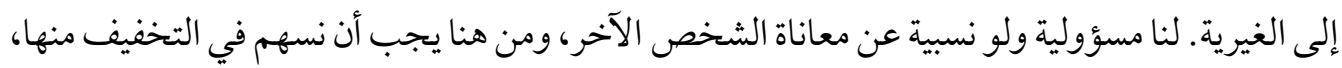

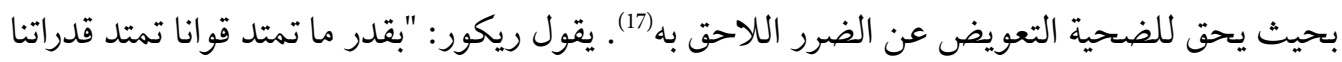

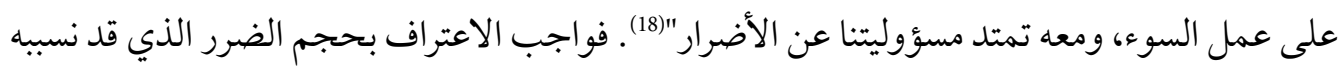

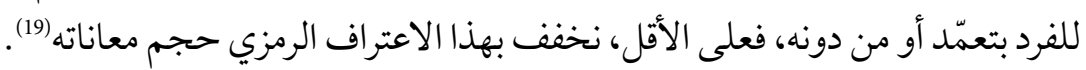

\section{2. القدرات والممارسات الاجتماعية}

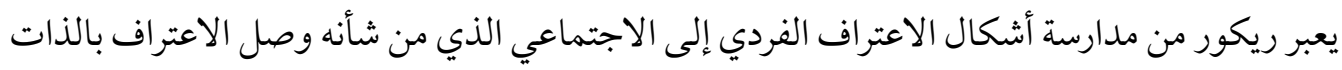

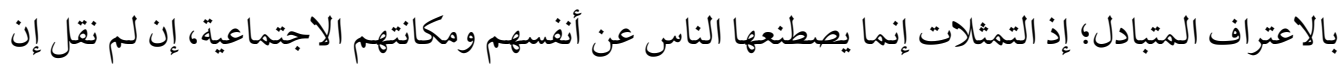

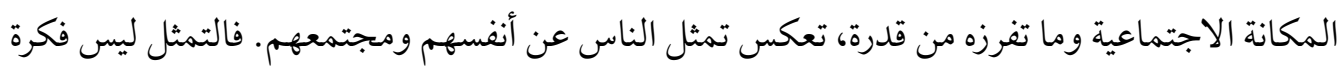

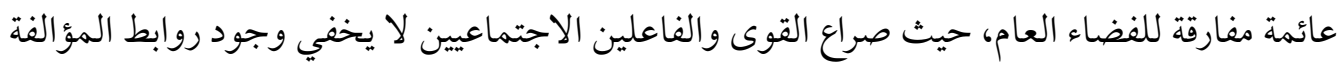

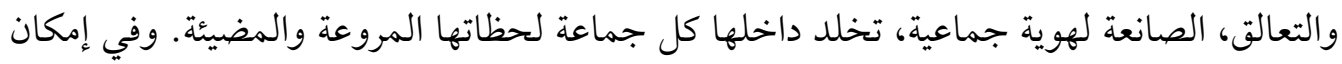

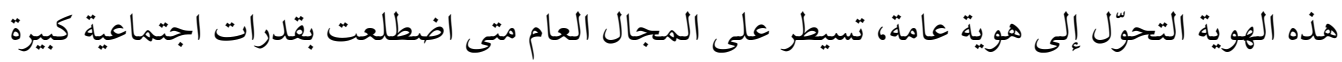

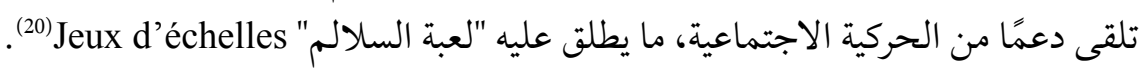

لا تقتصر الحركة الاجتماعية على التحول في المجال والهجرة من مكان إلى مكان، بل هنالك حركية

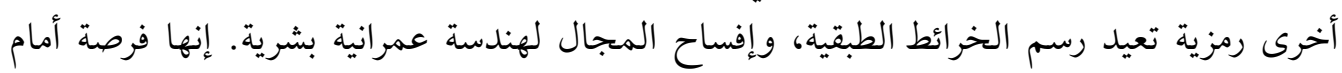

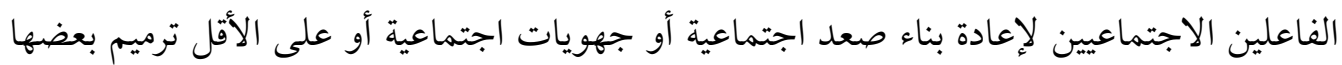

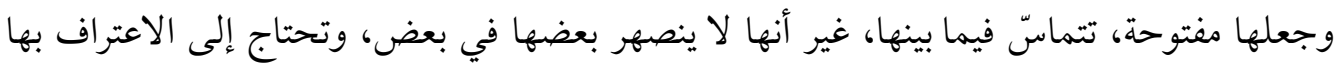

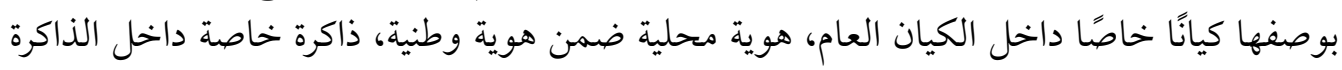

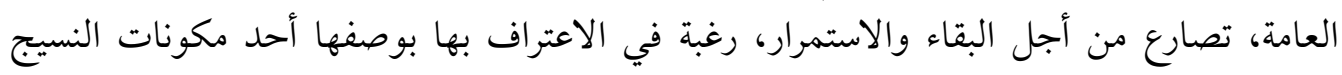

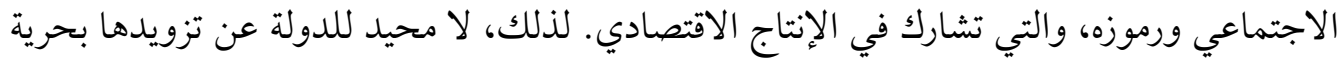

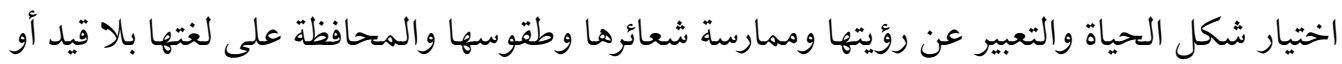

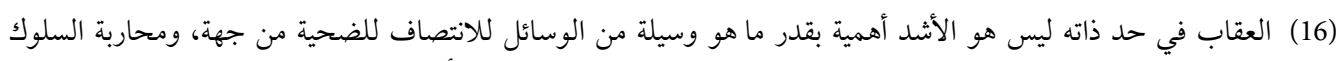

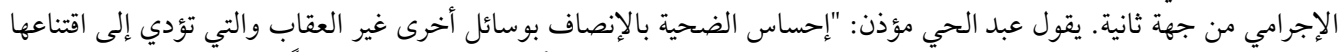

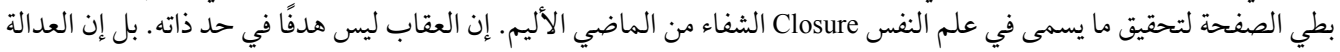

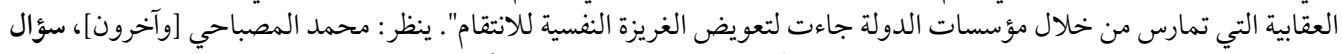

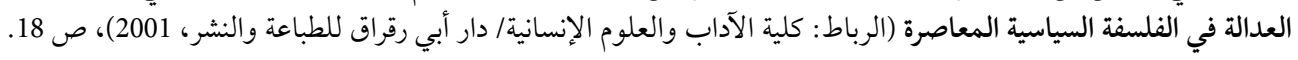

(17) Ricœur, p. 177.

(18) Ibid., p. 176.

(19) يقول عز العرب لحكيم بناني: "تختلف طبيعة الاعتراف أمام الضحية عن الاعتراف أمام القاضي. فالجاني يمارس عملية الضانية

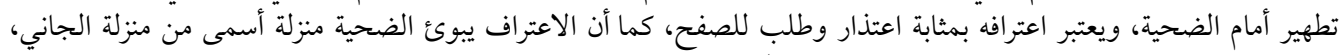

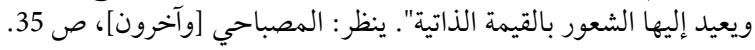

(20) Ricœur, p. 220. 


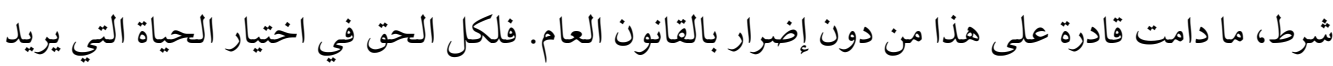

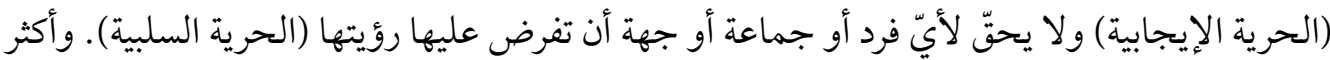

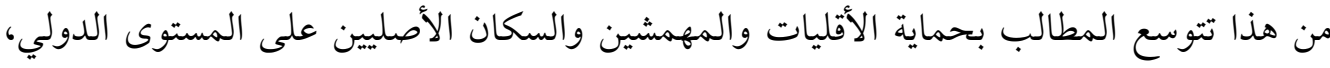
فلا نستغرب دعوة مجموعة من المفكرين لما يسمى بالتعدد الثقافي (21).

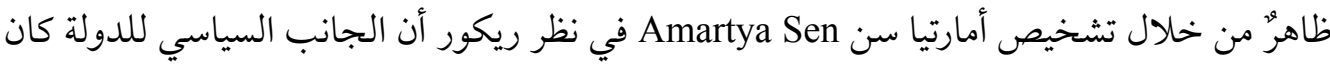

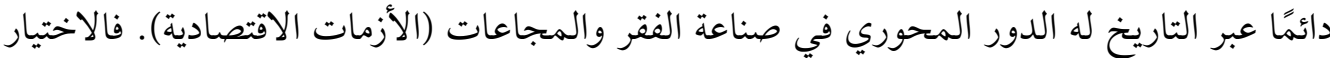

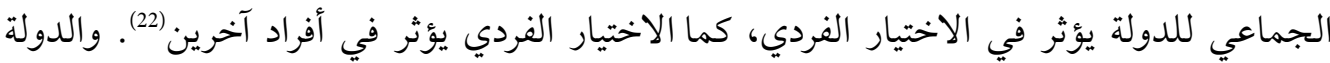

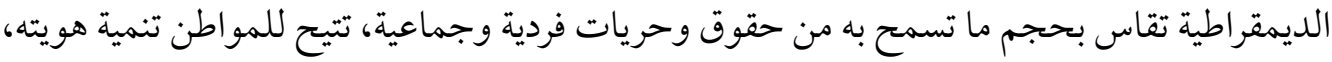

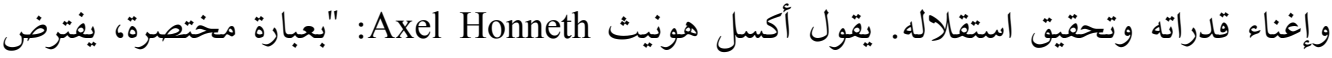

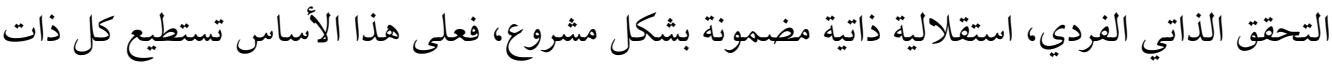

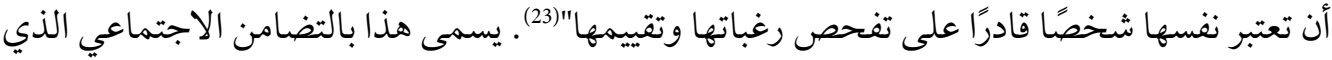

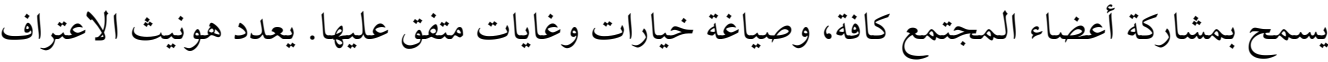

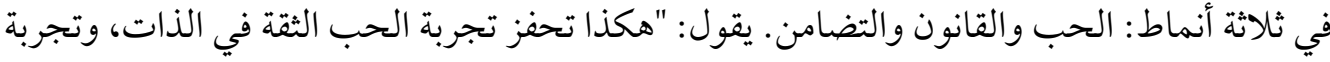

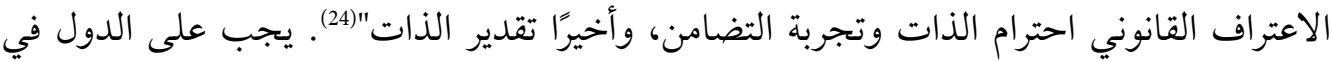

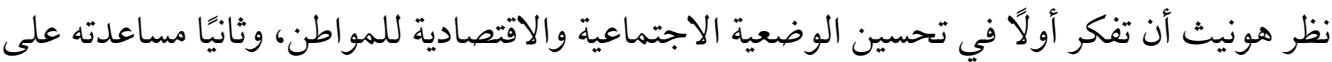

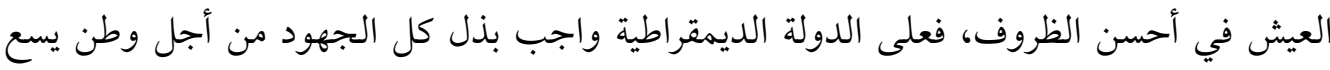

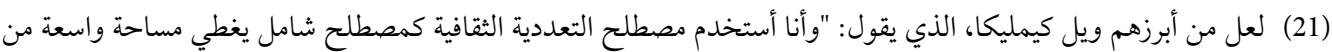

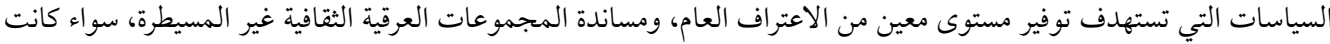

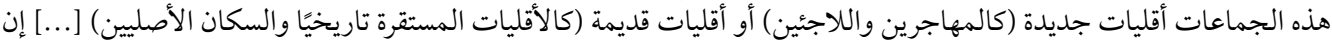

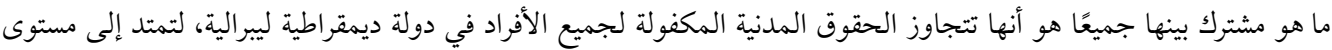

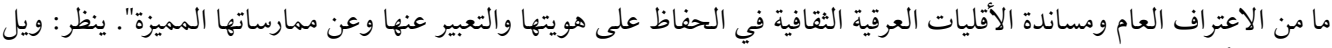

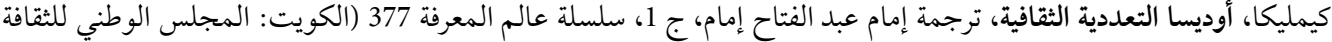

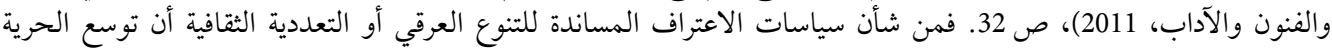

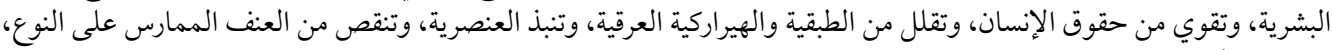

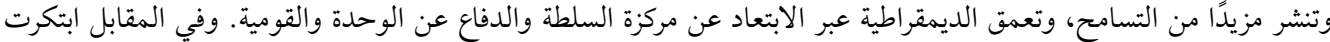

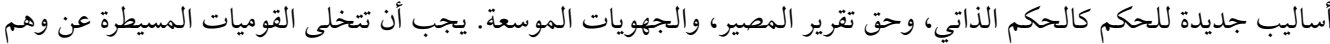

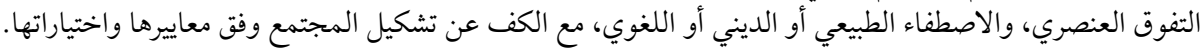

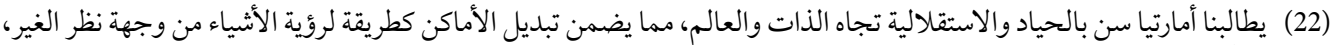

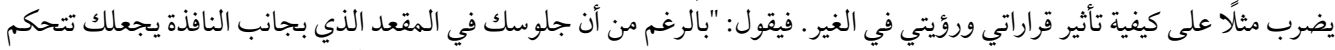

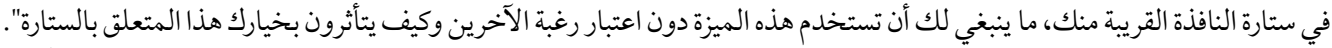

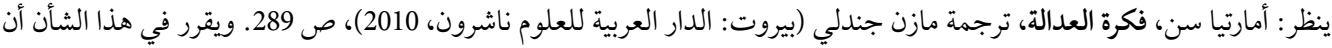

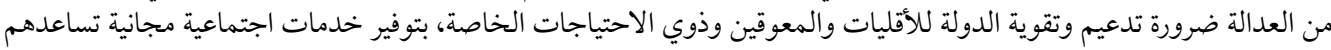

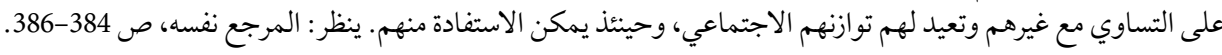

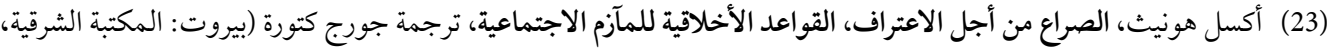
2015)، ص 2015)

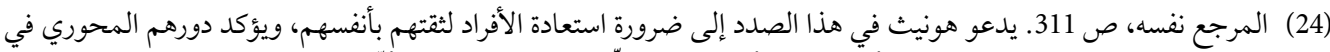

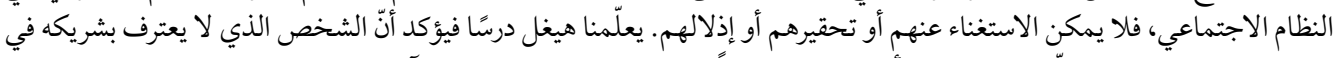

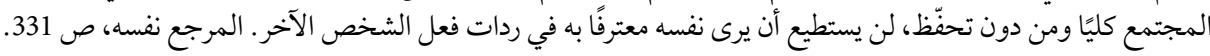




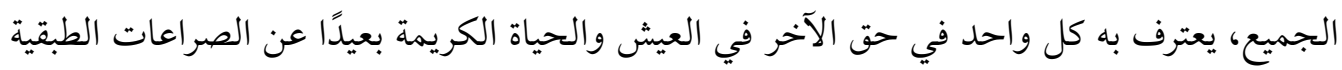
والتراتبات الاجتماعية التي تكرس جدلية السيد المتفوق والعبد فيد الخاضع المنهزم.

\section{ثُالثًا: الاعتتراف المتتبادل: جدل العبد والسيد}

يستهدف ريكور إثبات كيفية اشتقاق المبادلة من المخالفة، بتبيان أن التعارض لان لايعني القطيعة، بل هو

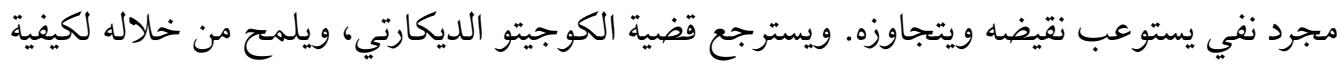

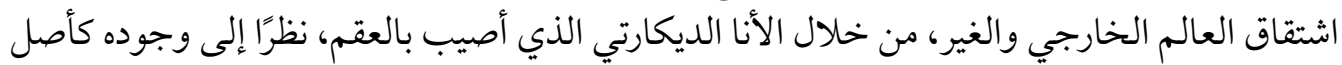

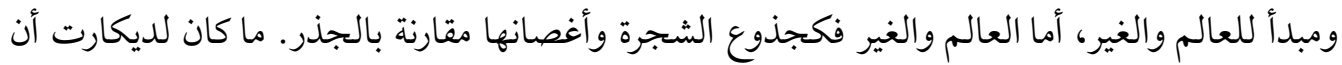

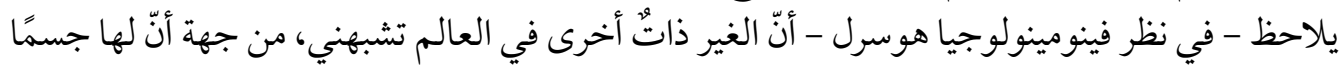

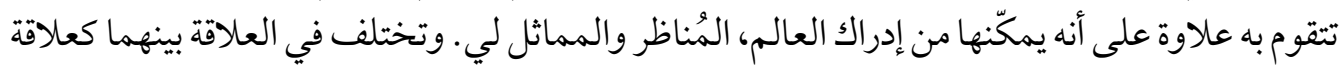

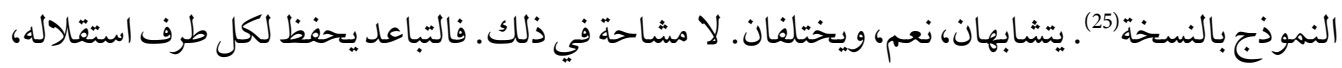
ويطلق عليه ريكور "التحصل التناسبي نaisie analogisante وتجربته في العالم من دون تشويه أو تنميط، ويهبه الوجود من أجل ذاته، ويثمن الغيرية في الغير.

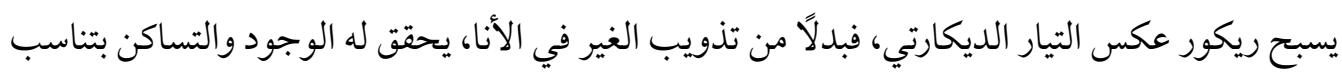

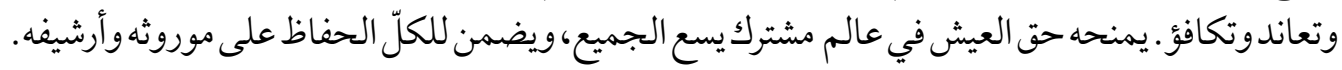

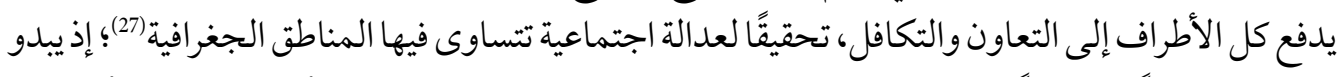

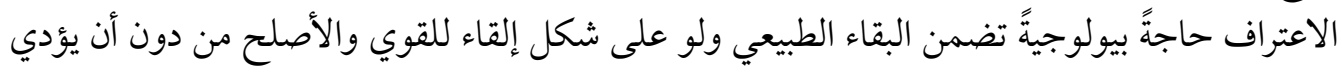

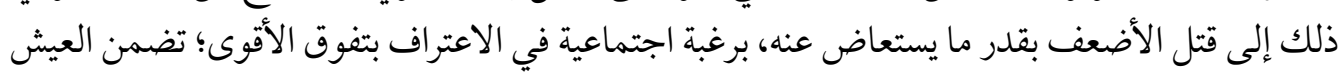

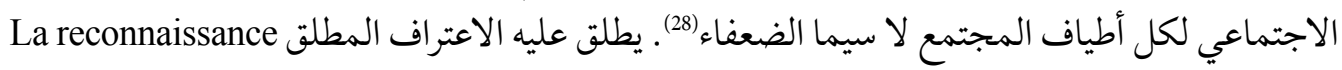

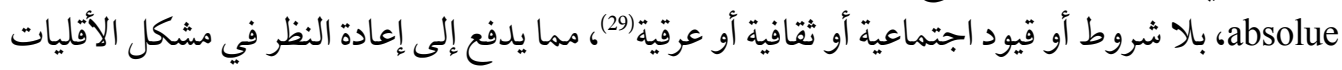
Les minorités

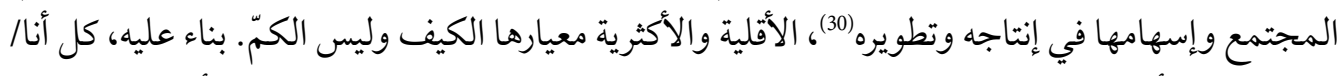

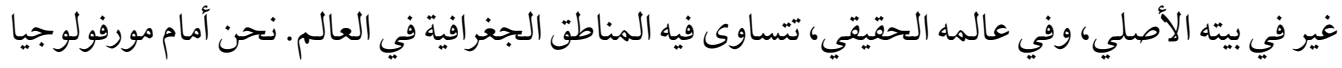

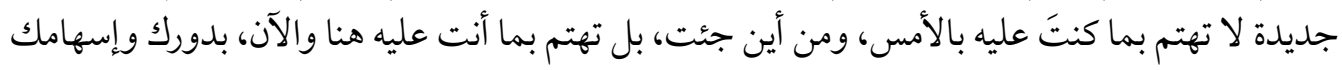

(25) Ricœur, p. 248.

(26) Ibid., p. 249

(27) Franck Fischbach, Fichte et Hegel La reconnaissance (Paris: PUF, 1999), p. 109.

(28) Ibid., p. 84.

(29) Ibid., p. 109

(30) يقول نوفل الحاج لطيف: "إذا كنت أعيش في مجتمع يقوم على المساواة في الحظوظ وأنه لدي طموحات معينة، ما سيقرر

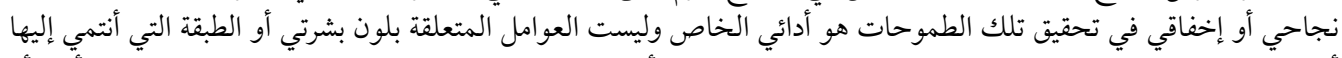

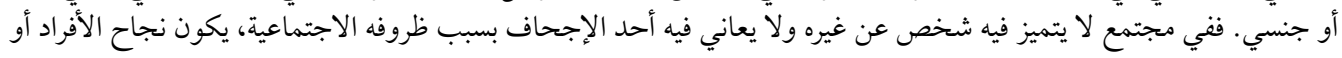

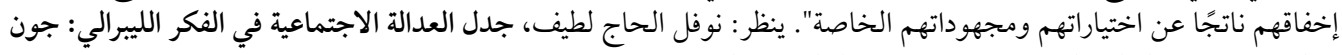

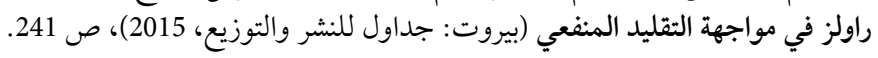


في المجتمع هي دعوة إلى حسن الضيافة التي نادى بها كانط في مشروعه للسلام الدائم، تعويضًا للمهاجر

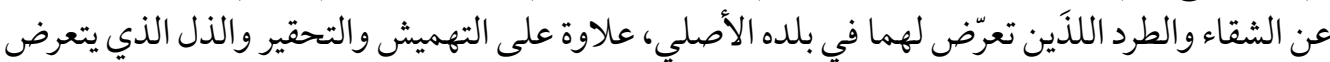

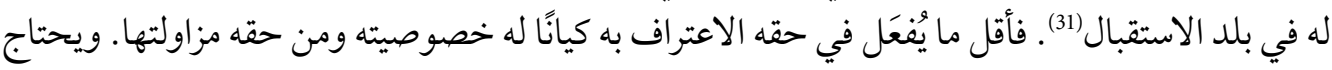

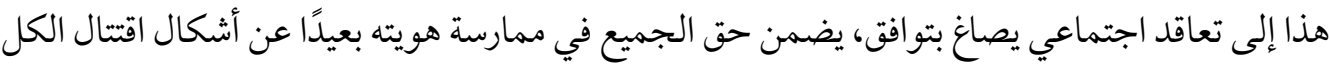

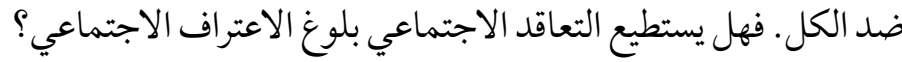

\section{1. تحدي هـوبر: التعاقد الاجتماعي ومَواطن ضعفه}

السياسة محاولة للبحث عن خير الفرد/ المواطن والمدينة، بغض الطرف عن انتماءات الأفراد الحزبية أو

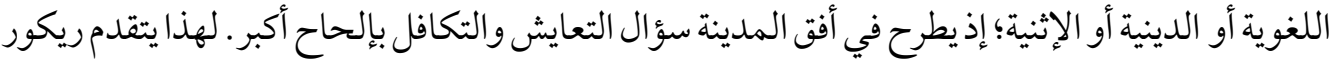

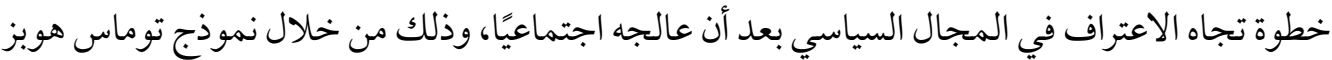
Thomas Hobbes

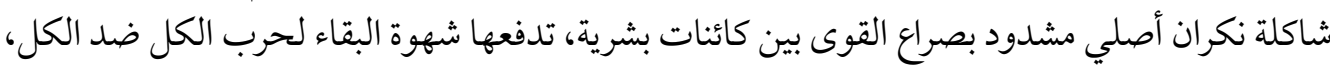

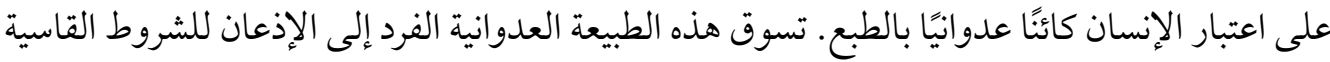

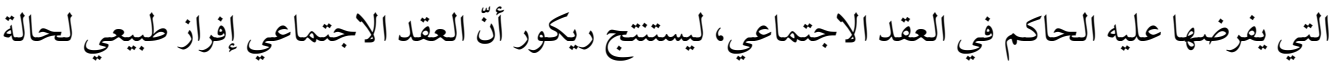

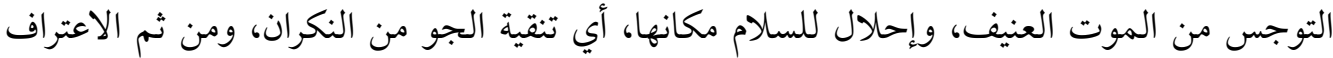

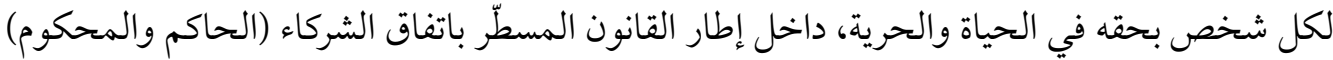

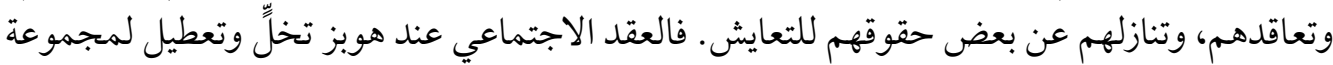

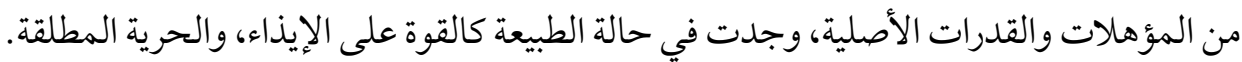

تأسيسًا على ما سبق، يستشف ريكور نقيصة في حق العقد الاجتماعي لهوبز يسميها "تحدي هوبز"؛

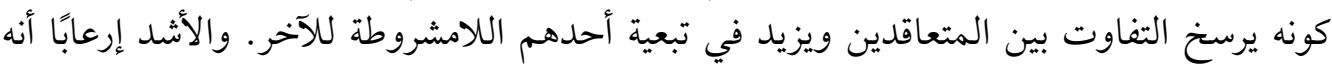

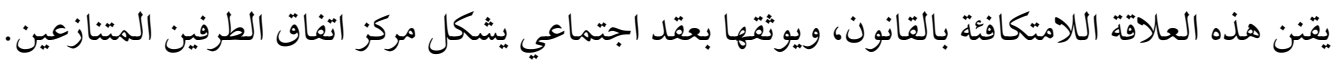

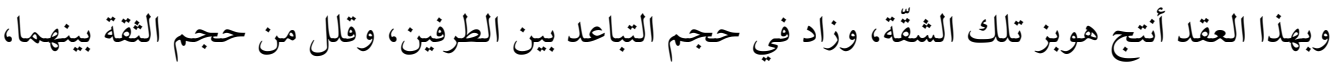

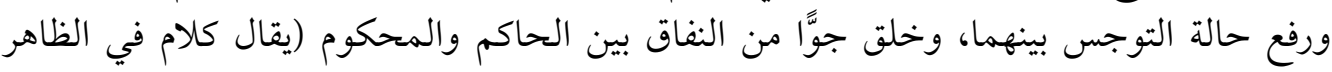

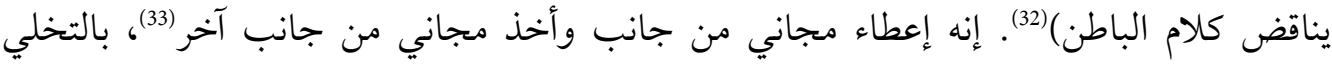

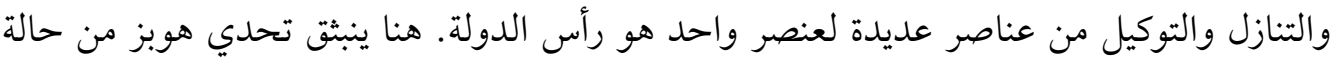

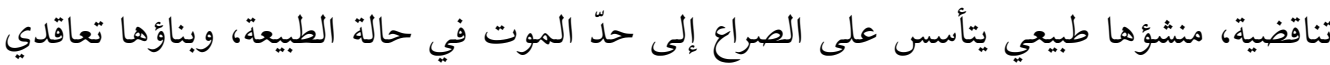

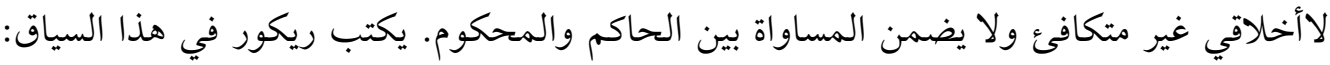

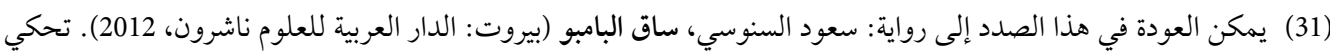

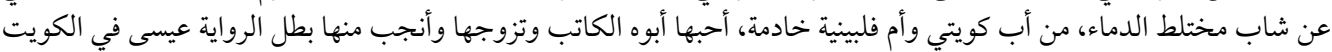

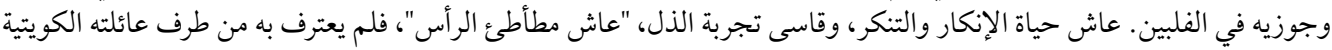

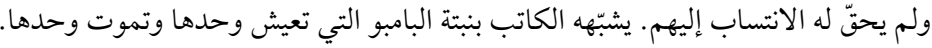

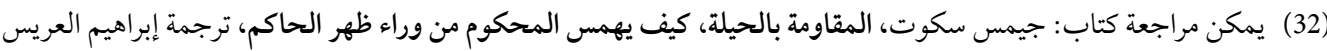

وميخائيل الخوري (بيروت: دار الساقي، 1995).

(33) Ricœur, p. 265. 


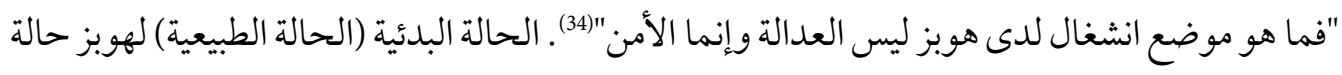

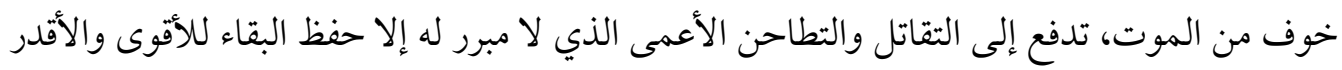

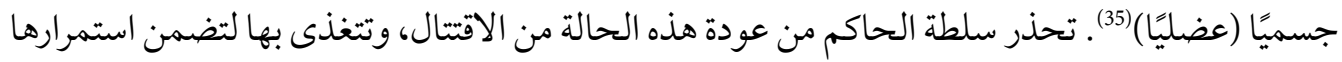

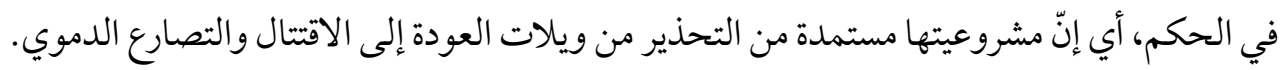

\section{2. هيغل والخلل في الهوية: التعارف وتجربة الاحتقار}

يتحول الإنكار الهوبزي في شخص الحاكم المتسلط الذي لا يمثل في شخصه كل الإرادات الخاصة.

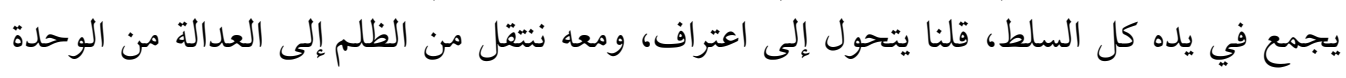

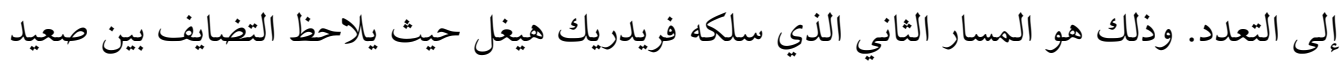

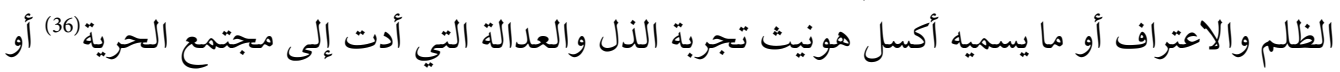

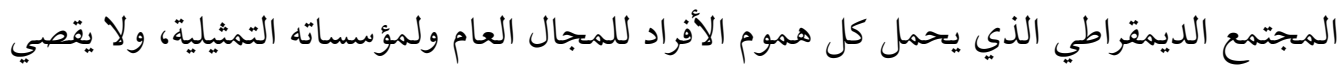

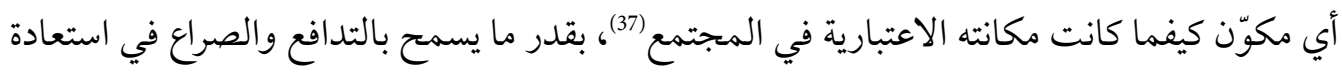

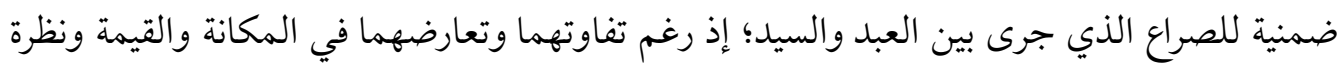

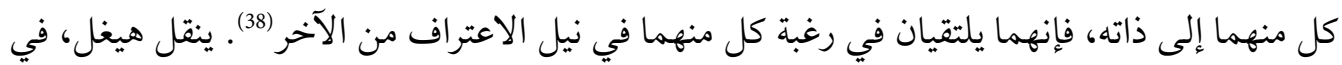

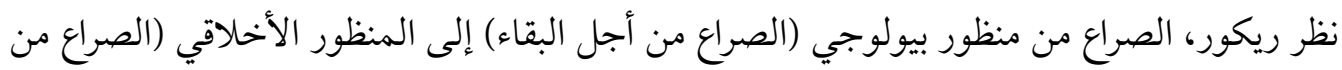

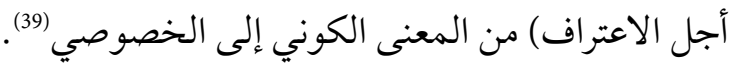

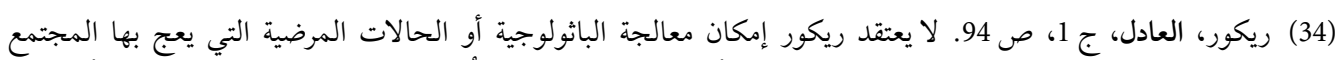

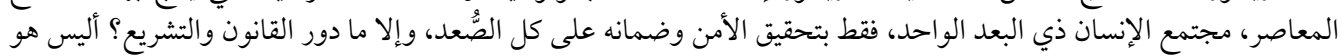

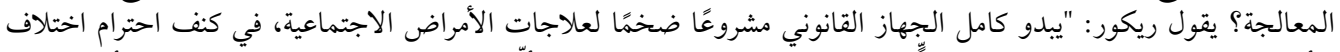

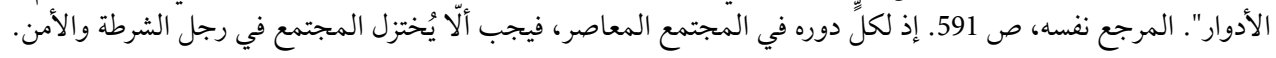

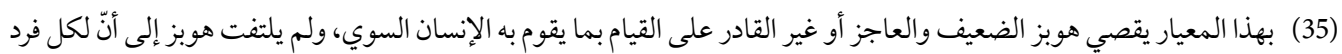

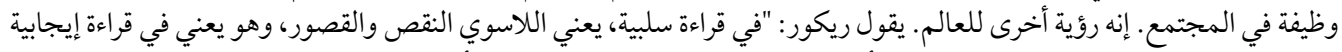

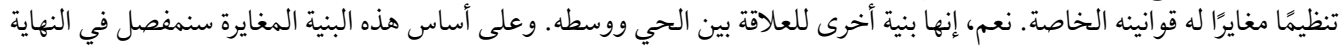

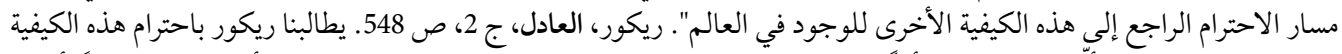

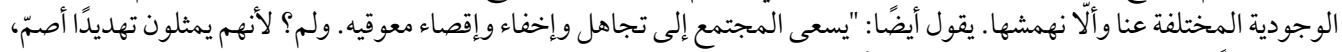

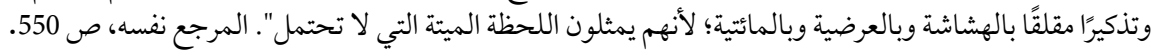

(36) Louis Carré, Axel Honneth: Le droit de la reconnaissance (Paris: Michalon Editeur, 2013), p. 30.

(37) Ibid., p. 277.

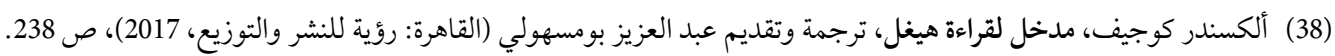

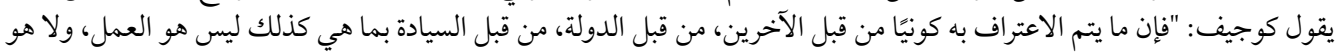

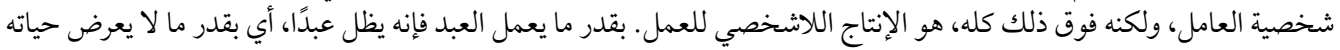

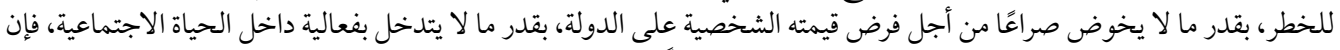

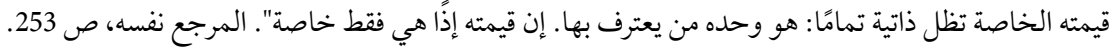
(39) Ricœur, p. 277;

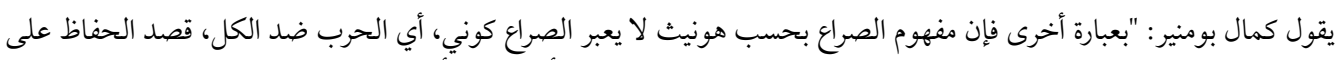

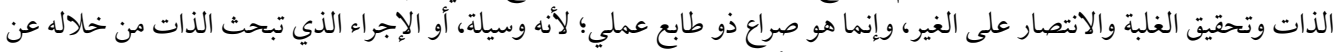

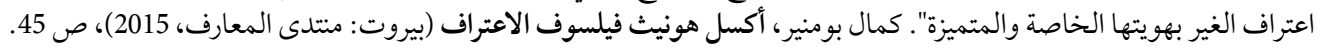




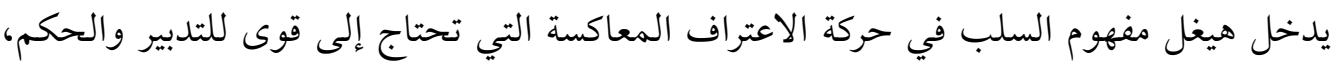

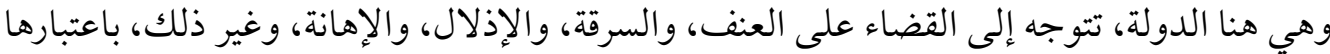

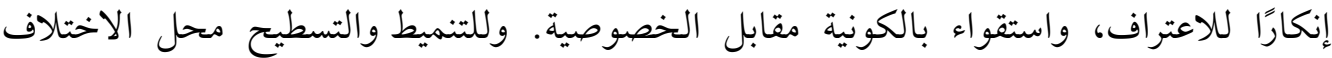

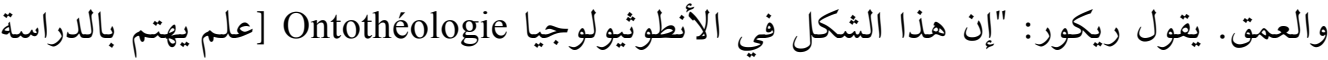

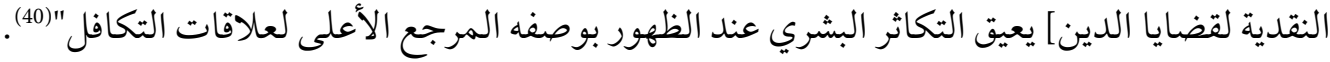

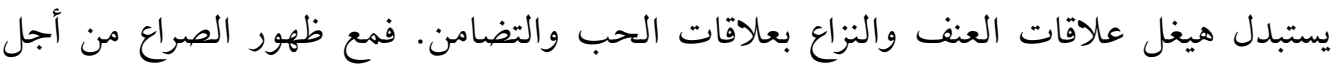

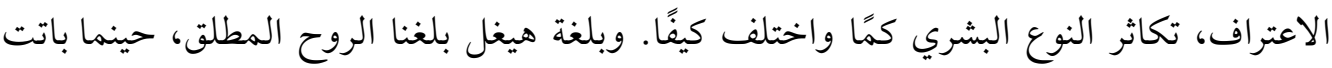

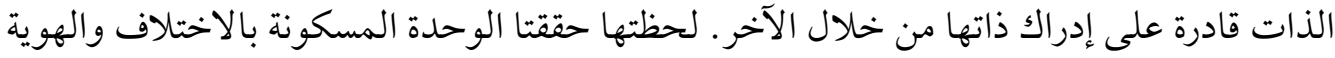

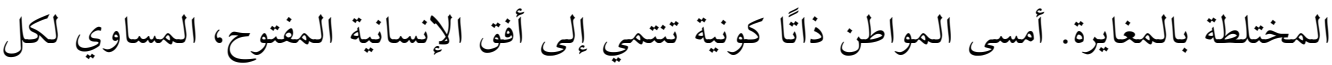

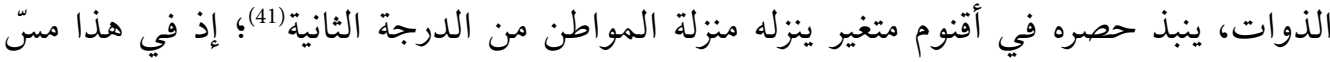

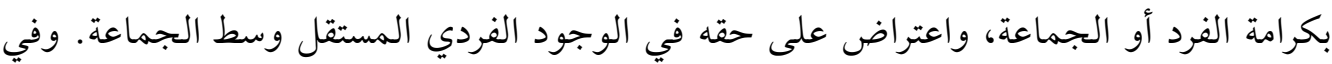

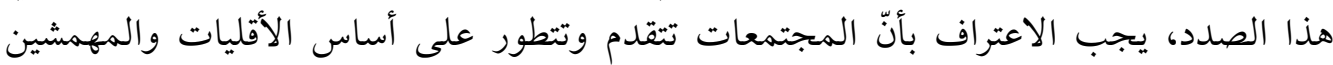

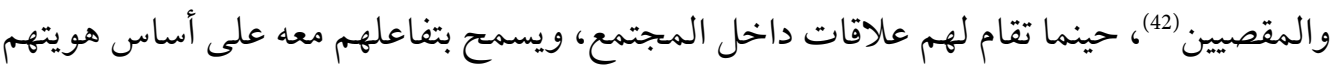

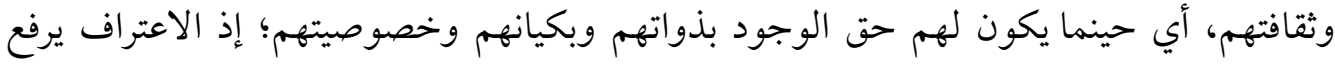

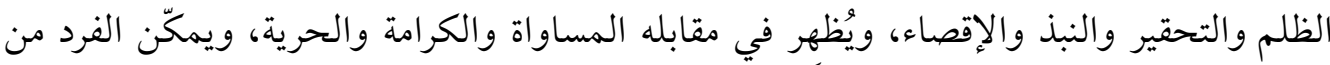

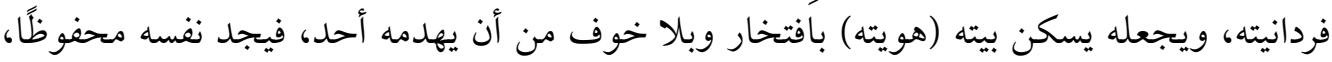

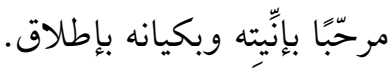

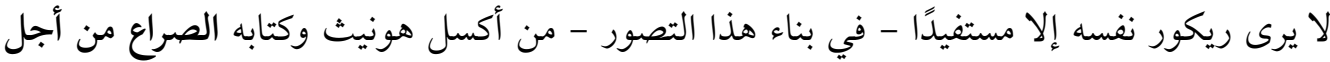
الاعتراف لكنه يقترح الإدلاء بعدة اعتبارات تكميلية، تمنح تجارب الاعتراف هنداء بعدًا سلميًا. صيغ منظور هونيث على أنقاض نظرية هوبز، المكونة من التنافس والحذر والفخر أو الو الكبرياء.

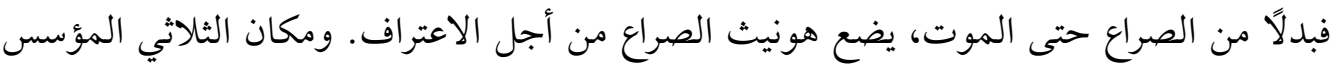

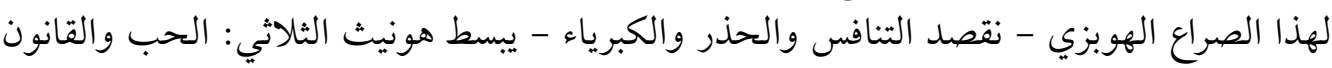

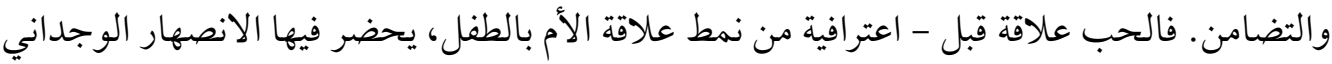

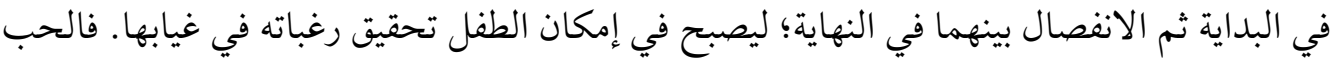

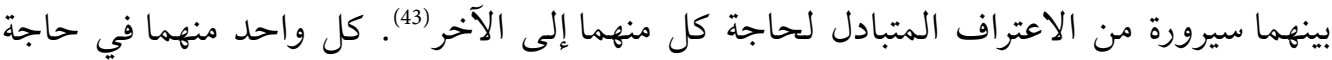

Ricœur, p. 283 (40) وما بين معقوفين إضافة من الباحث للتوضيح.

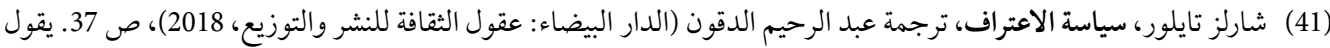

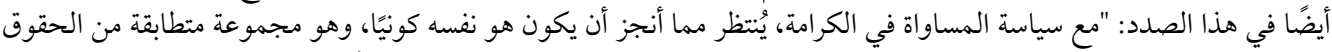

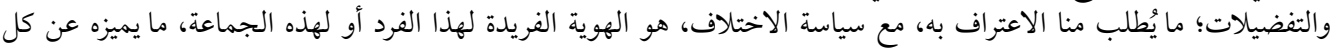

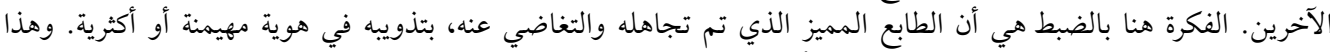

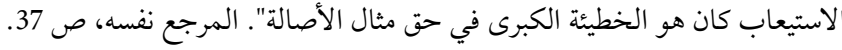


ملحّة إلى الآخر، ولكل منهما دور في مساعدة الآخر على اكتشاف ذاته؛ الأم بصفتها أمًا والطفل

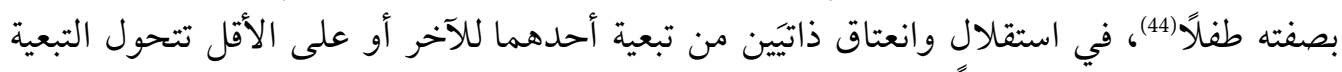

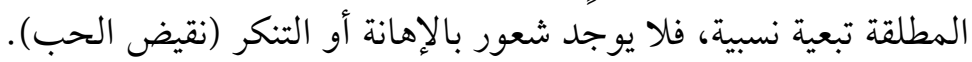

يخوض ريكور في حديث عن العائلة وما يجمعها من اتصال نسلي، بفضله يمنع إتيان المحارم بين

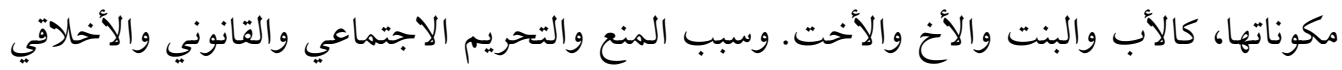

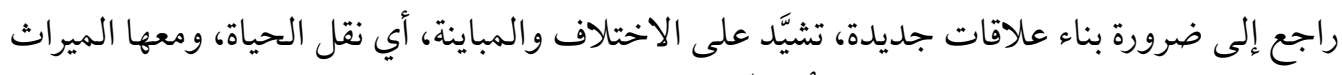

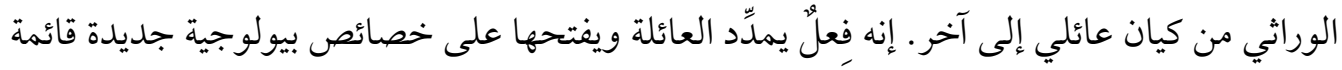

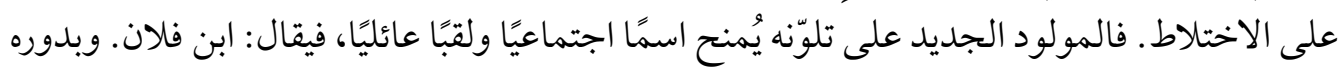

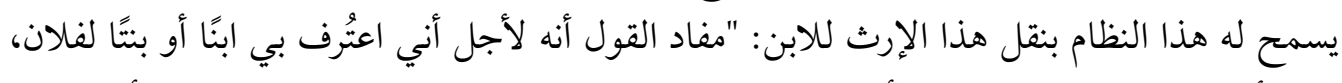

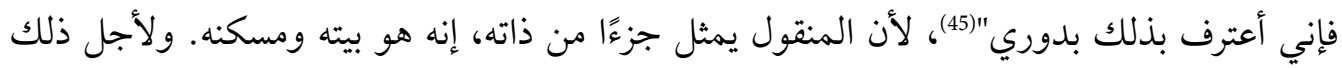

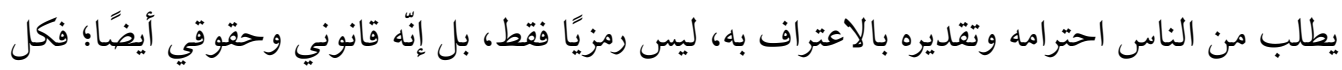

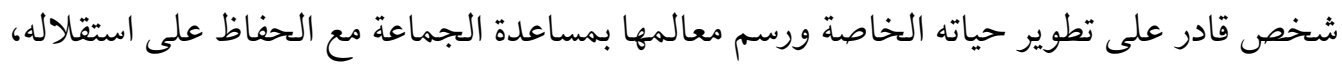

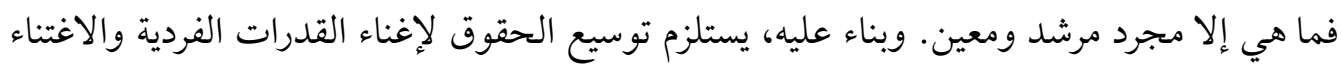

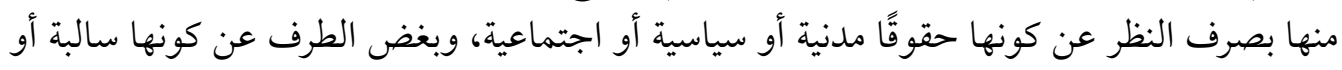

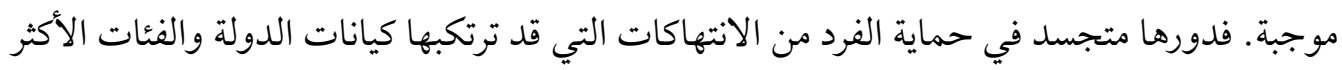

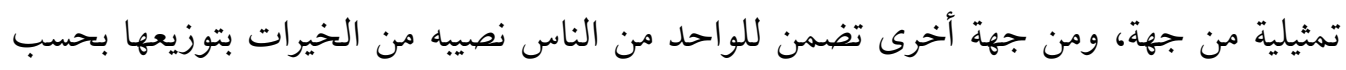

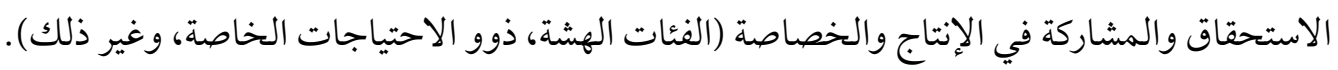

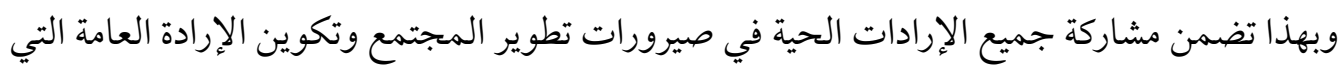

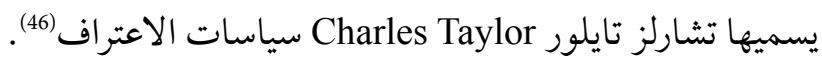

يعتقد تايلور أنّ ما وصلنا إليه اليوم من ثقافة وتقدم اقتصادي مدينون به لجميع الثقافات وعديد الفئات

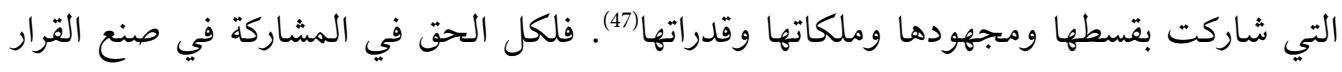

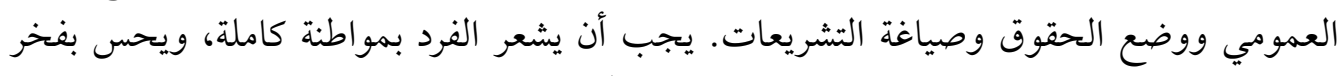

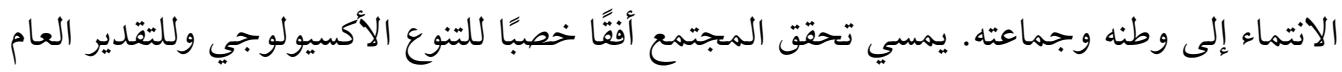

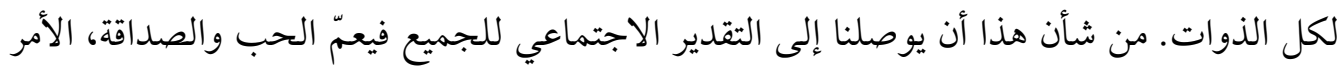
الذي في إمكانه تزويدهم بالثقة بالنفس ويالأمن العاطفي.

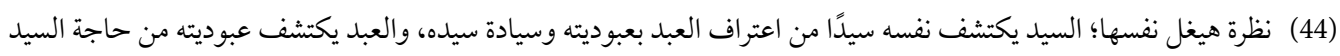

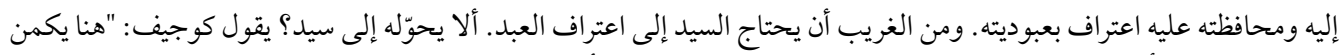

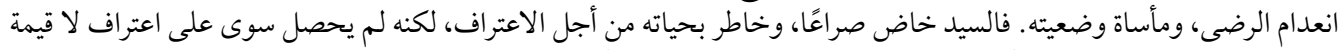

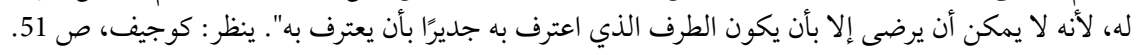
(45) Ricœur, p. 304.

$$
\text { تايلون، ص 75 75. 53؛ سن، ص } 497 .
$$




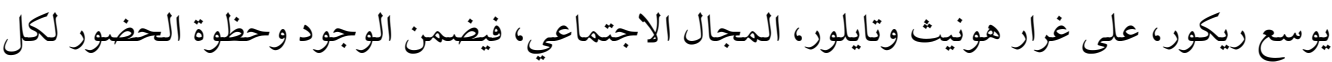

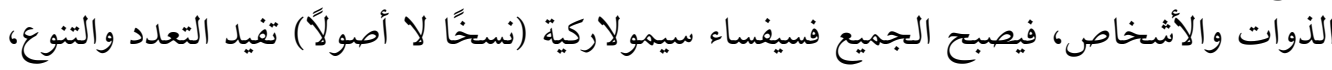

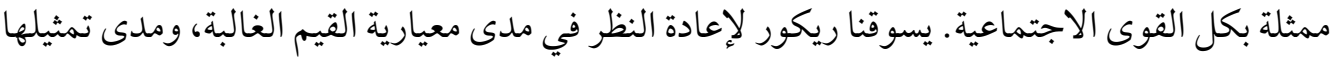

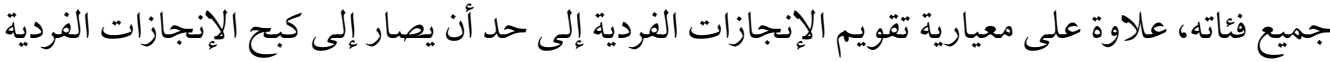

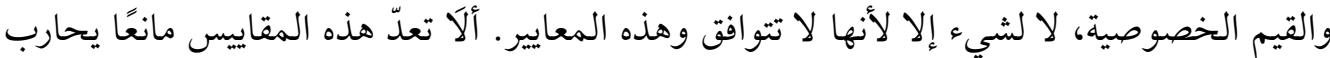

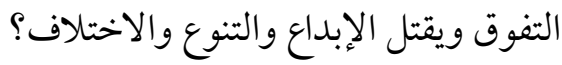

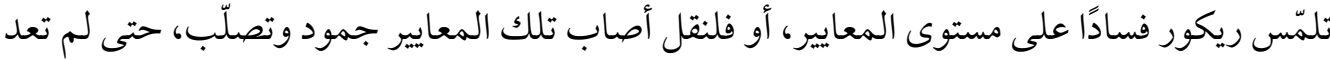

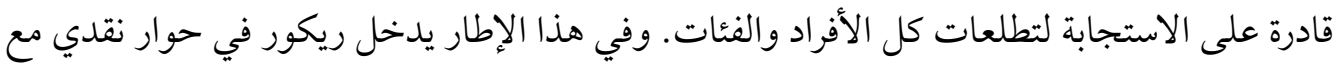

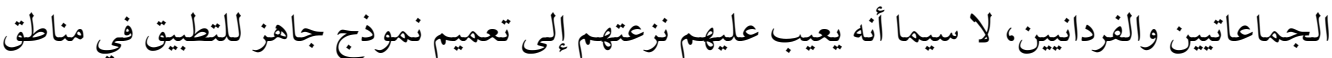

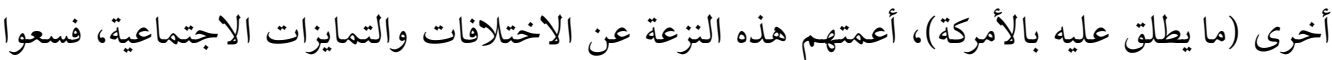

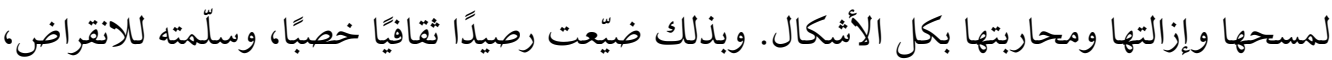

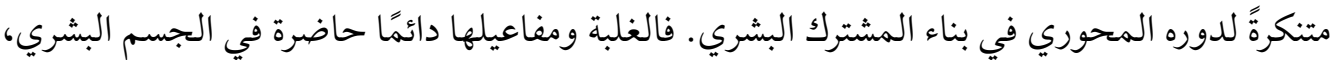

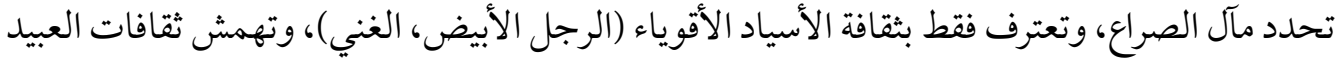

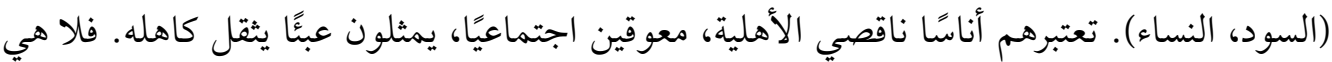

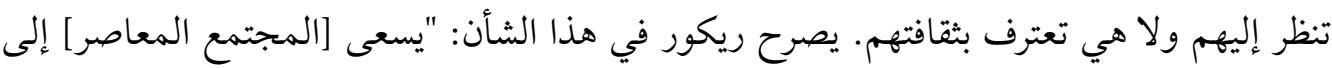

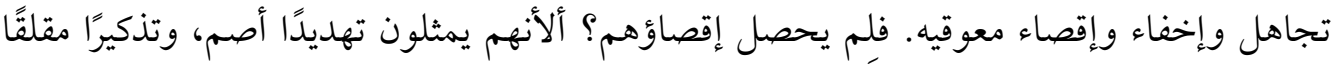

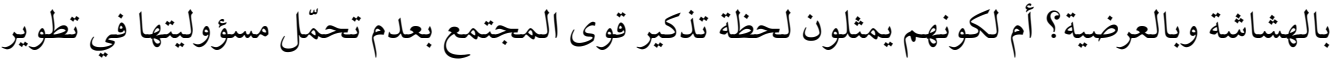

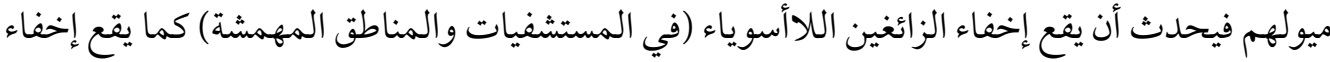

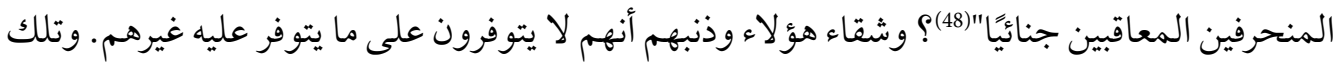

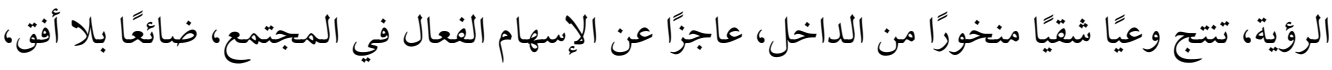

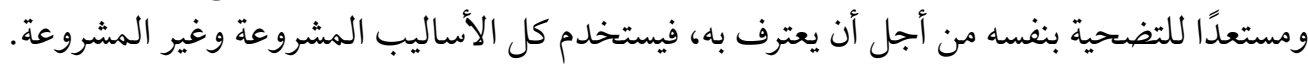

\section{3. الصـراع مـن أجـل الاعتراف وحالات السلاهم}

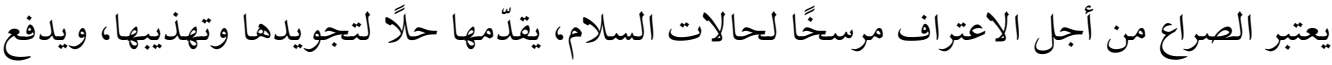

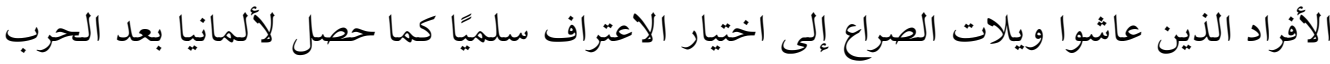

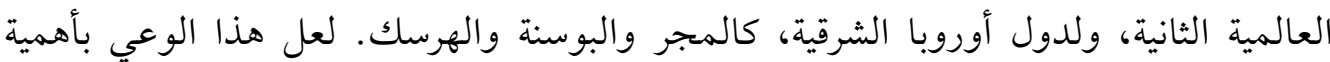

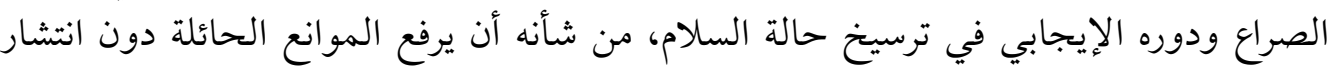

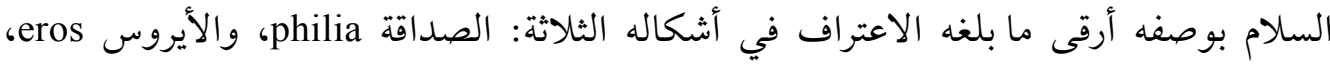

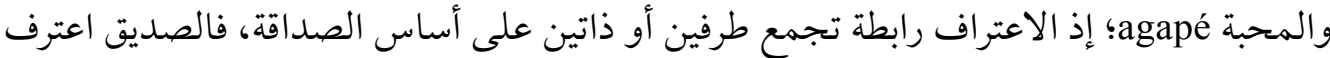

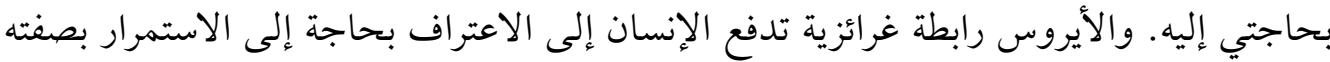

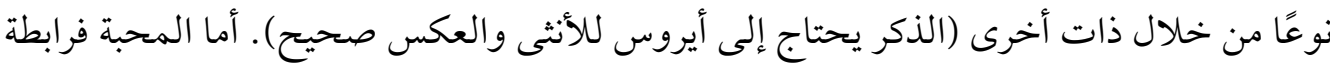


وجدانية تدفع صاحبها إلى التعلق بمن يحب والاستعداد للتضحية من أجله، وهي أقصى أنواع

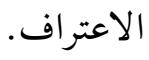

يلاحظ أنّ الاعتراف نوع من المبادلة العادلة؛ تحفظ حقوق الطرفين وكرامتهما، وتستلزم عطاء الطرفين

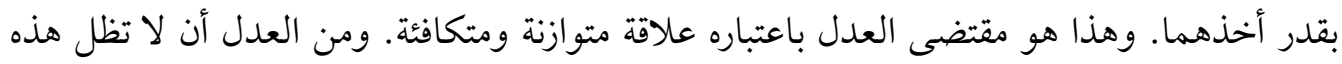

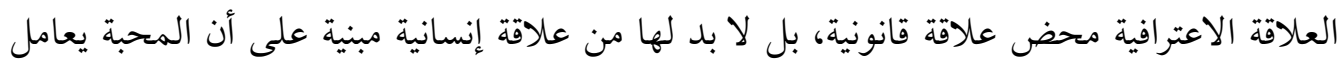

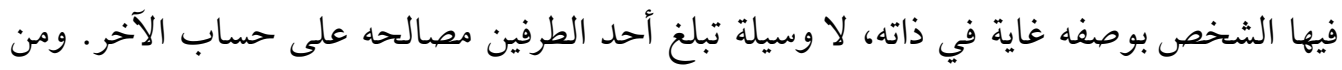

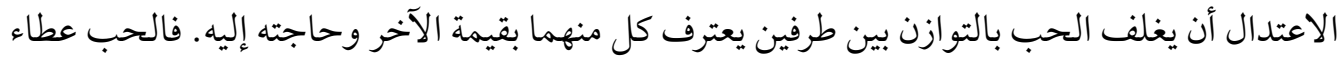

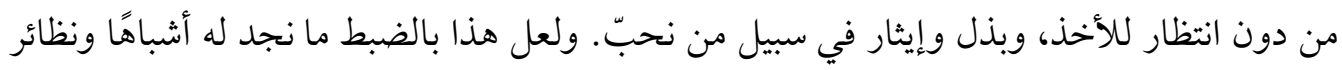

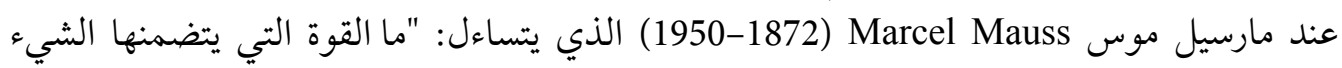

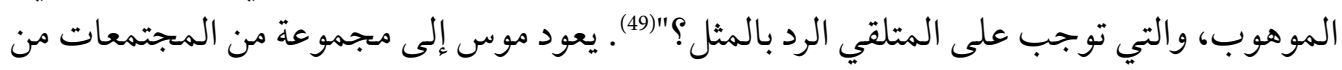

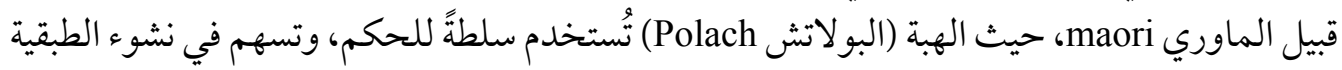

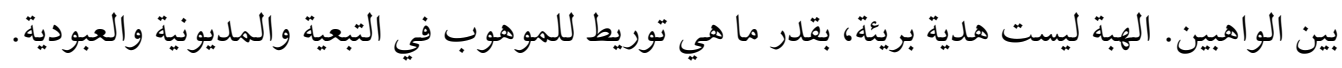

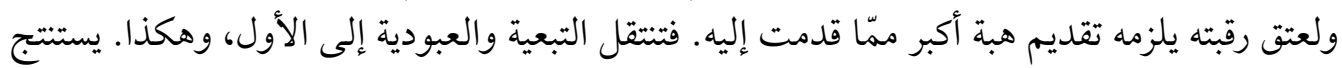

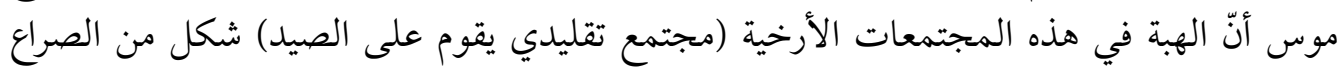

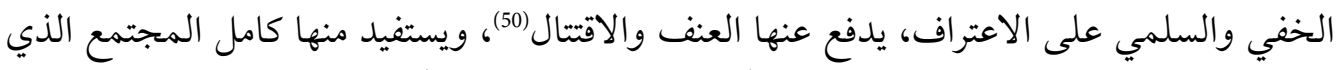

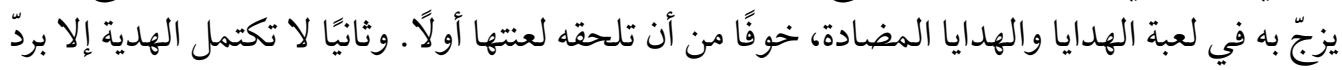

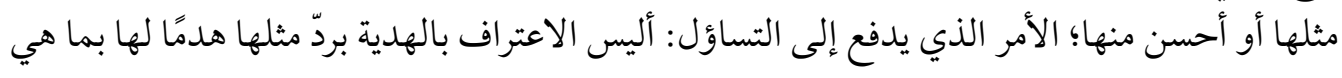

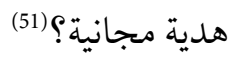

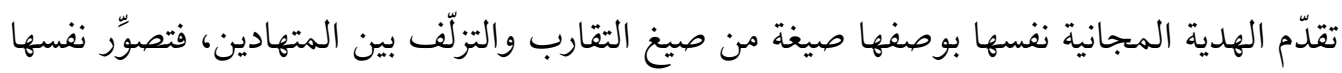

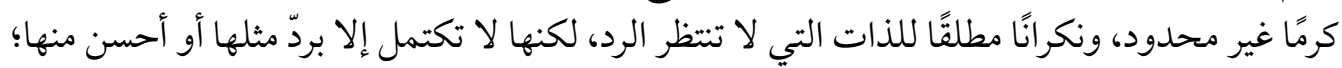

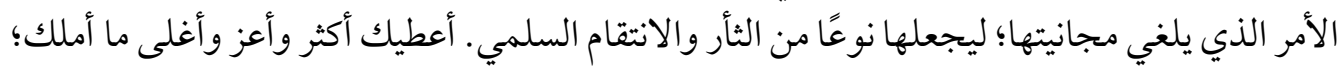

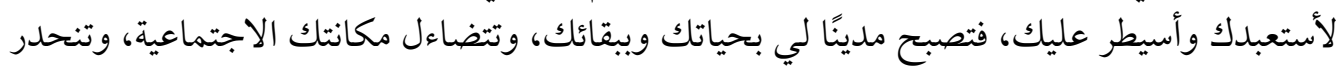

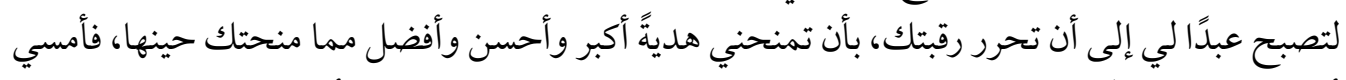

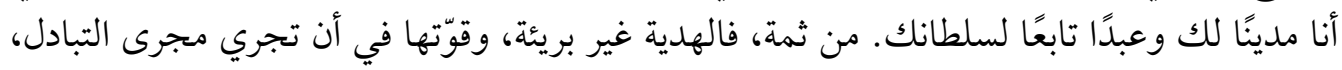

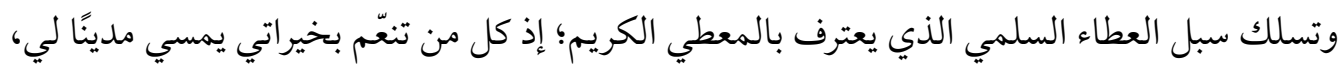

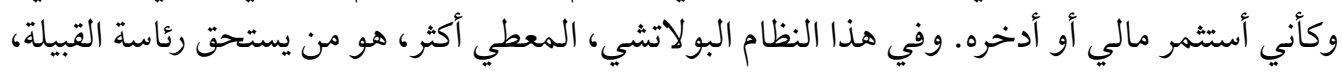

(49) مارسيل موس، مقالة في الهبة، أشكال التبادل في المجتمعات الأرخية وأسبابه، ترجمة محمد الحاج سالم (طرابلس:

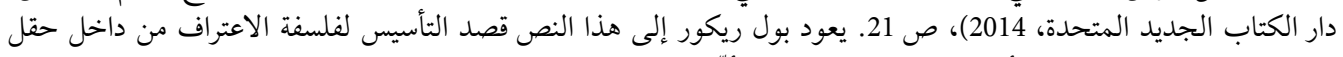

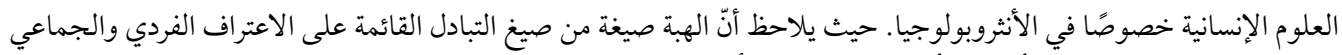

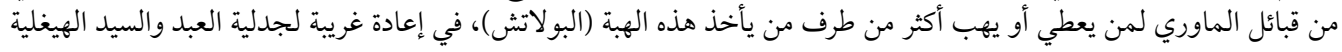




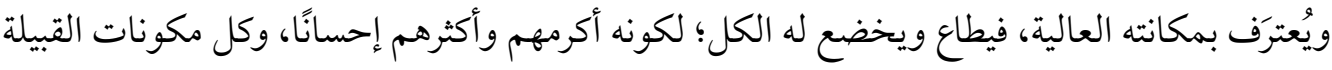

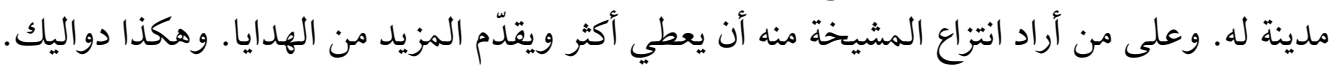

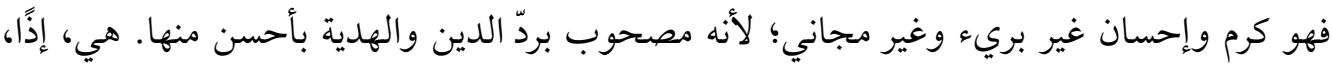

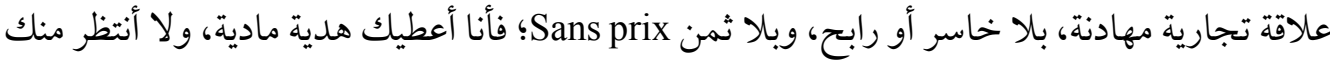

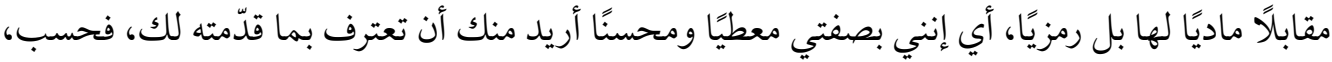

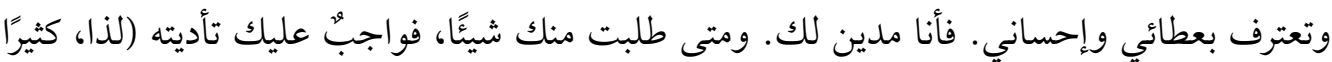

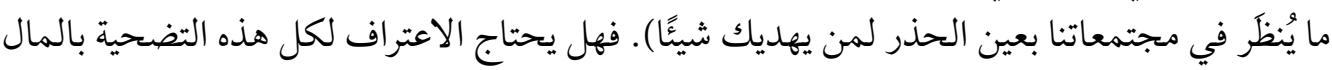

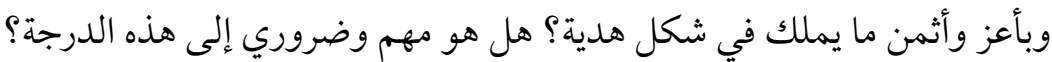

\section{خَاتمة}

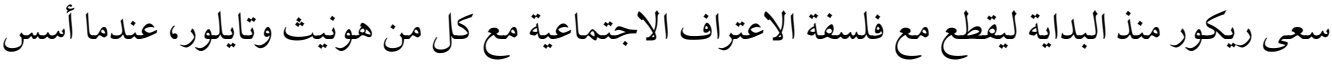

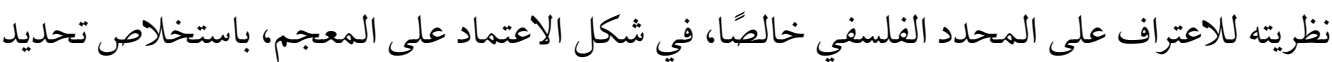

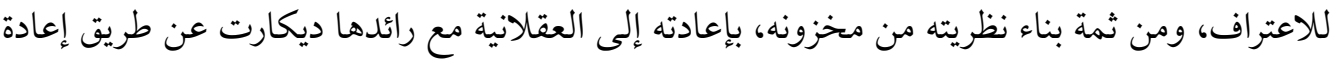

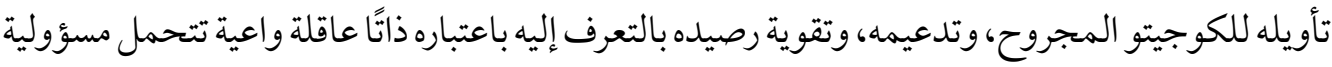

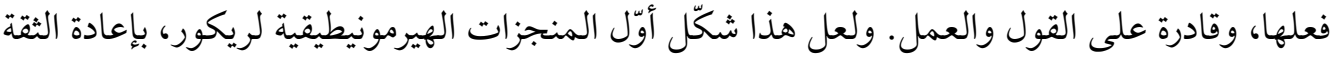
لفلسفة الوعي. وهو ما لا يتفق وفلسفات الاعتراف التي بدأته من هيغل في نظرية جدل التهل العبد العبد والسيد.

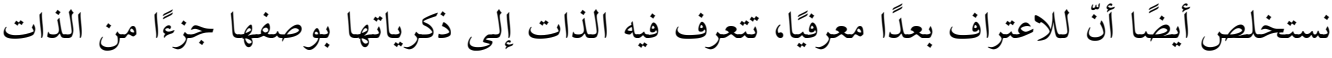

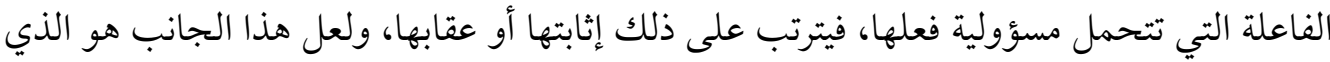

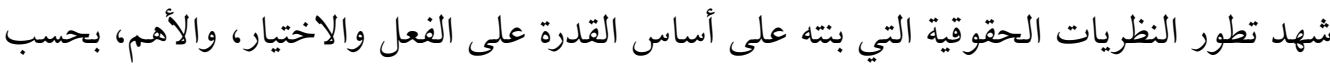
ريكور، أن هنالك ذاتًا ينسب إليها الفعل.

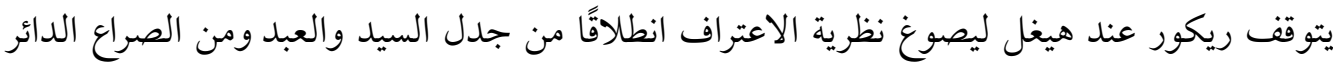

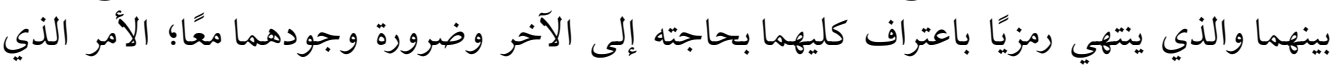

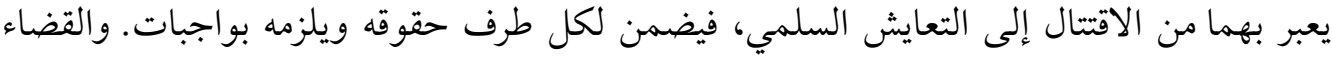

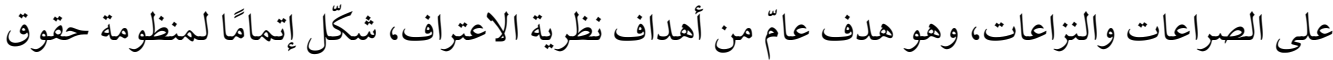

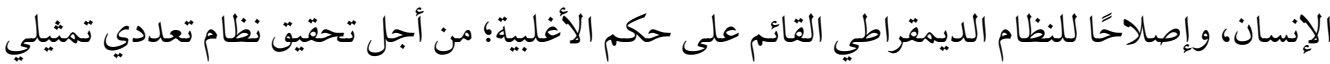

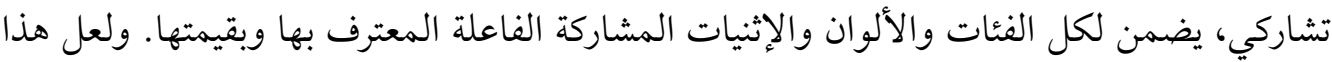

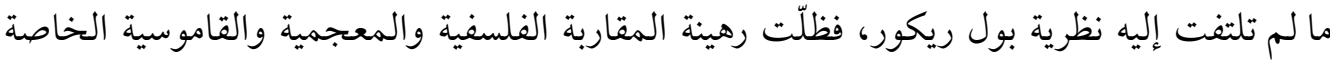

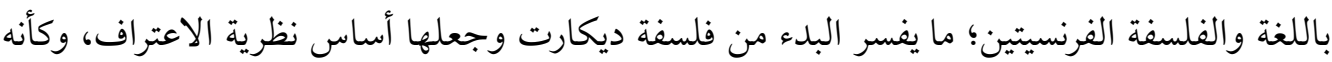
نوع من الإقصاء لباقي اللغات والفلسفات في الإسهام الفعلي في هذه النظرية.

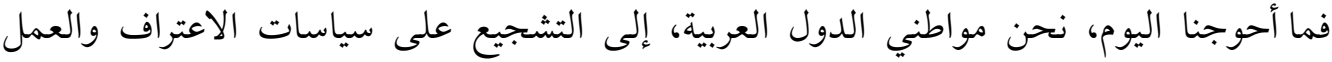

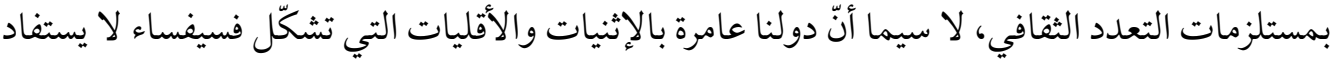




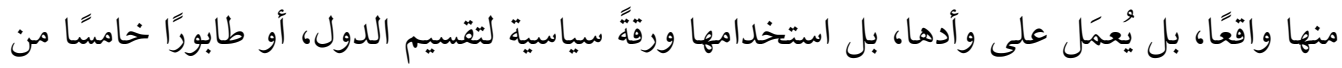

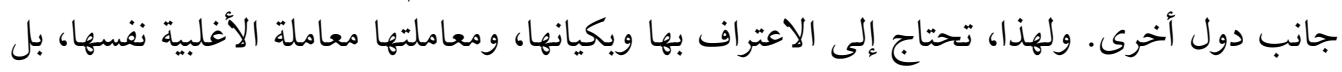

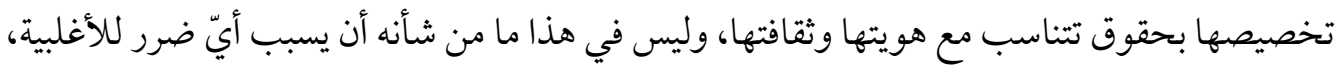

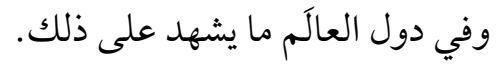

\section{References}

\section{المراجع}

العربية

$$
\text { بومنير، كمال. أكسل هونيث فيلسوف الاعتراف. بيروت: منتدى المعارف، } 2015 .
$$

تايلور، شارلز. سياسة الاعتراف. ترجمة عبد الرحيم الدقون. الدار البيضاء: عقول الثقافة للنشر والتوزيع، دائور، فاركز، 2018. ديكارت، رينيه. العادل. ترجمة محمد البحري [وآخرون]. قرطاج: المجمع التونسي للعلوم والآداب

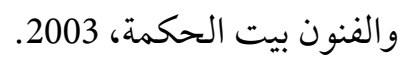

. الذات عينها كآخر . ترجمة جورج زيناتي. بيروت: المنظمة العربية للترجمة، 2005. . حديث الطريقة. ترجمة وشرح وتعليق عمر الشارني. بيروت: المنظمة العربية للترجمة، بئه

، سيرة الاعتراف. ترجمة فتحي إنقزو. مراجعة محمد محجوب. تونس: المركز الوطني

.

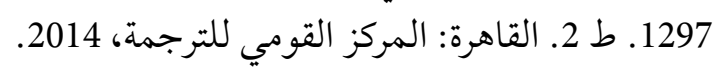

الحاج لطيف، نوفل. جدل العدالة الاجتماعية في الفكر الليبرالي: جون راولز في مواجهة التقليد المنفعي. بيروت: جداول للنشر والتوزيع، 2015. سكوت، جيمس. المقاومة بالحيلة، كيف يهمس المحكوم من وراء ظهر الحاكم. ترجمة إبراهيم

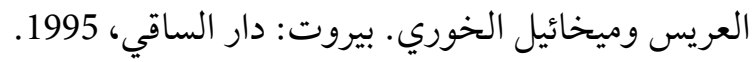
سن، أمارتيا. فكرة العدالة. ترجمة مازن جندلي. بيروت: الدار العربية للعلوم ناشرون، 2010. السنوسي، سعود. ساق البامبو. بيروت: الدار العربية للعلوم ناشرون، 2012.

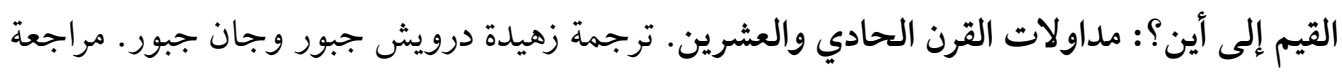

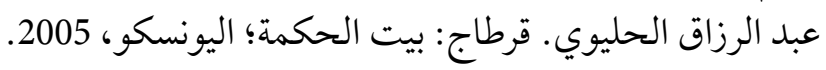
كوجيف، ألكسندر. مدخل لقراءة هيغل. ترجمة وتقديم عبد العزيز بومسهولي. القاهرة: رؤية للنشر والتوزيع، 2017. 
كيمليكا، ويل. أوديسا التعددية الثقافية. ترجمة إمام عبد الفتاح إمام. ج 1. سلسلة عالم المعرفة 377.

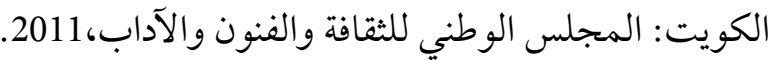

المصباحي، محمد [وآخرون]. سؤال العدالة في الفلسفة السياسية المعاصرة. الرباط: كلية الآداب

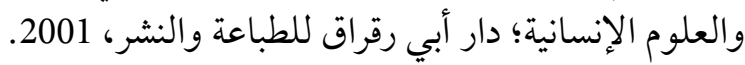

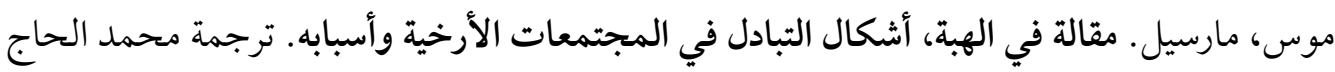

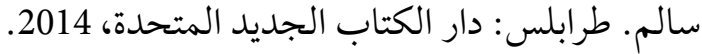
هونيث، أكسل. الصراع من أجل الاعتراف، القواعد الأخلاقية للمآزم الاجتماعية. ترجمة جورج كتورة.

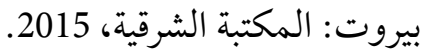

الأجنبية

Carré, Louis. Axel Honneth: Le droit de la reconnaissance. Paris: Michalon Editeur, 2013.

Fischbach, Franck. Fichte et Hegel La reconnaissance. Paris: PUF, 1999.

Ricœur, Paul. Parcours de la reconnaissance. Paris: Gallimard, 2004. 